Portland State University

PDXScholar

\title{
Evaluation of Transportation Microenvironments \\ Through Assessment of Cyclysts' Exposure to Traffic-Related Particulate Matter
}

\author{
Linda A. George \\ Portland State University \\ Miguel A. Figliozzi \\ Portland State University, figliozzi@pdx.edu \\ Christopher M. Monsere \\ Portland State University, monsere@pdx.edu \\ Christine M. Kendrick \\ Portland State University \\ Alexander Y. Bigazzi \\ Portland State,University, abigazzi@gmail.com \\ Follow this and additional works at: https:/9pdxscholar.library.pdx.edu/trec_reports \\ Part of the Transportation Commons, Urban Studies Commons, and the Urban Studies and Planning \\ Eemprimptipage for additional authors

\section{Let us know how access to this document benefits you.}

\section{Recommended Citation}

George, Linda, Miguel Figliozzi, Christopher Monsere, Christine M. Kendrick, Alexander Y. Bigazzi and Adam Moore. Evaluation of Transportation Microenvironments Through Assessment of Cyclysts' Exposure to Traffic-Related Particulate Matter. OTREC-RR-11-16. Portland, OR: Transportation Research and Education Center (TREC), 2010. https://doi.org/10.15760/trec.5

This Report is brought to you for free and open access. It has been accepted for inclusion in TREC Final Reports by an authorized administrator of PDXScholar. Please contact us if we can make this document more accessible: pdxscholar@pdx.edu. 


\section{Authors}

Linda A. George, Miguel A. Figliozzi, Christopher M. Monsere, Christine M. Kendrick, Alexander Y. Bigazzi, and Adam Moore 

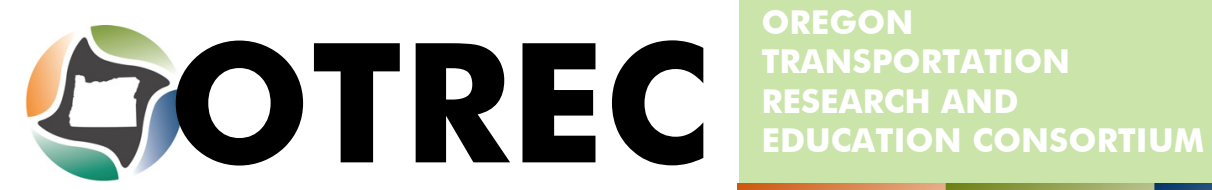

FINAL REPORT

Evaluation of Transportation Microenvironments Through Assessment of Cyclists' Exposure to Traffic-Related Particulate Matter

OTREC-RR-11-16

July 2011 



\title{
EVALUATION OF TRANSPORTATION MICROENVIRONMENTS THROUGH ASSESSMENT OF CYCLISTS' EXPOSURE TO TRAFFIC-RELATED PARTICULATE MATTER
}

\author{
Final Report \\ OTREC-RR-11-16
}

by

Linda George, Miguel Figliozzi, Chris Monsere

Christine Kendrick, Alex Bigazzi, Adam Moore

Portland State University

for

Oregon Transportation Research and Education Consortium (OTREC)

P.O. Box 751

Portland, OR 97207

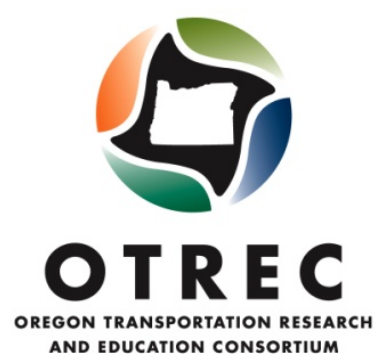

July 2011 



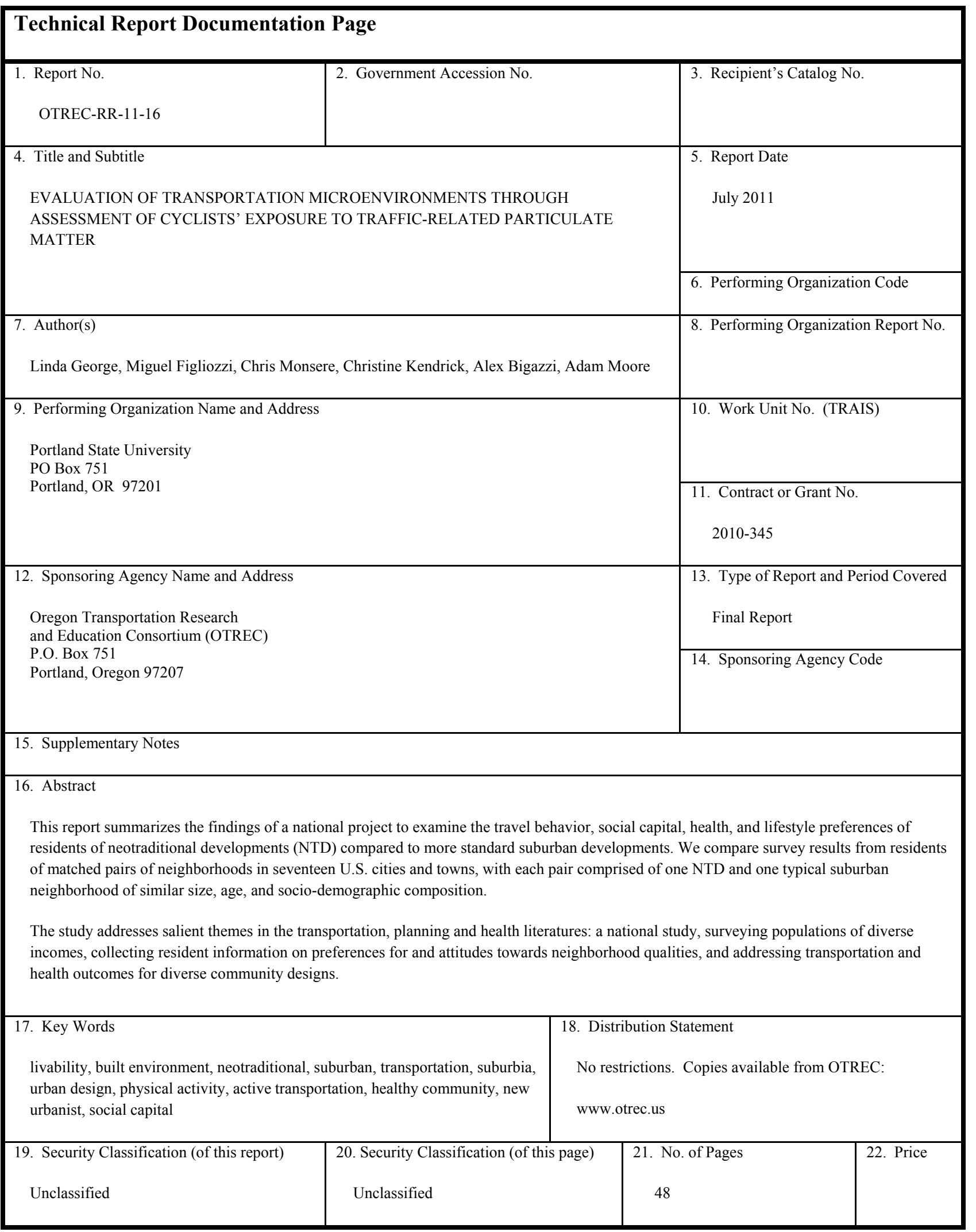




\section{ACKNOWLEDGEMENTS}

This research was funded by the Oregon Transportation Research and Education Consortium (OTREC) and the Miller Foundation.

\section{DISCLAIMER}

The contents of this report reflect the views of the authors, who are solely responsible for the facts and the accuracy of the material and information presented herein. This document is disseminated under the sponsorship of the U.S. Department of Transportation University Transportation Centers Program and the City of Portland in the interest of information exchange. The U.S. Government and the City of Portland assume no liability for the contents or use thereof. The contents do not necessarily reflect the official views of the U.S. Government and the City of Portland. This report does not constitute a standard, specification, or regulation. 


\section{TABLE OF CONTENTS}

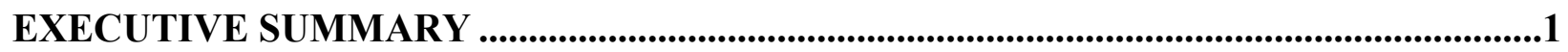

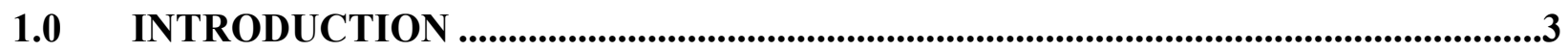

1.1 AIR QUALITY AND PROXIMITY TO TRAFFIC STREAM .....................................

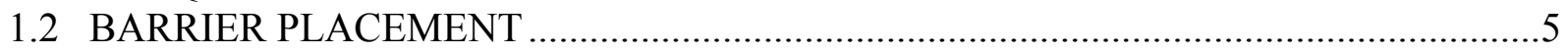

1.3 RESEARCH QUESTIONS..................................................... 5

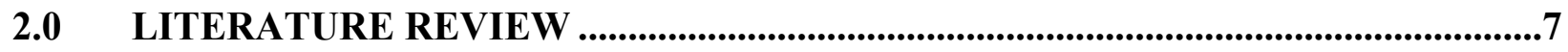

2.1 PROXIMITY TO ROADWAY STUDIES ………....................................................

2.1.1 Extent of Traffic Data Used in Personal Exposure Studies ......................................

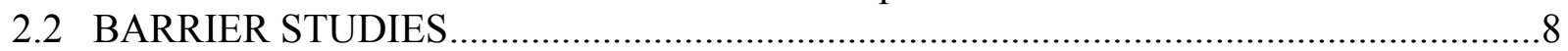

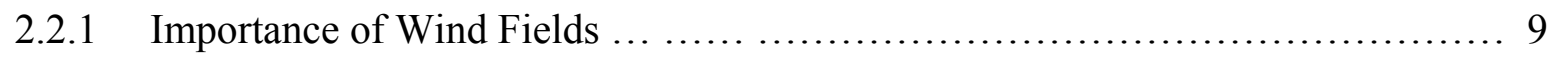

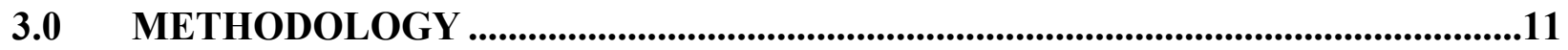

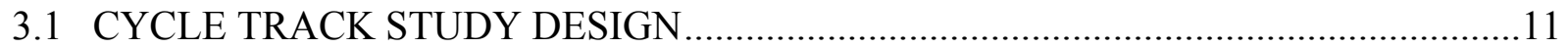

3.2 PASSIVE SHIELDING WITH NOISE BARRIER STUDY DESIGN ……….................13

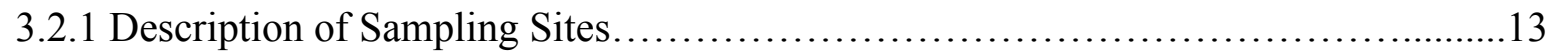

3.2.2 Sampling and Instrumentation................................................. 15

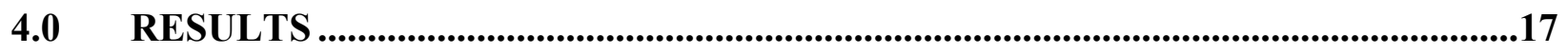

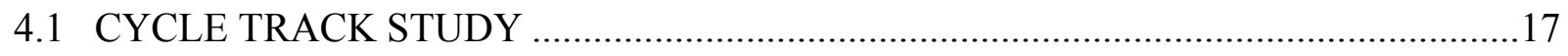

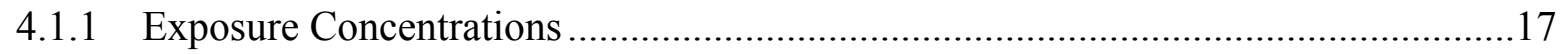

4.1.2 Comparison with Measured Traffic ...................................................................... 18

4.2 PASSIVE SHIELDING WITH NOISE BARRIERS .............................. 24

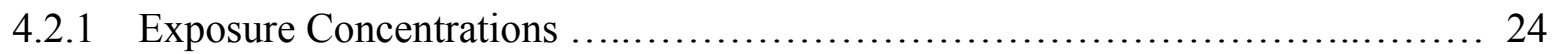

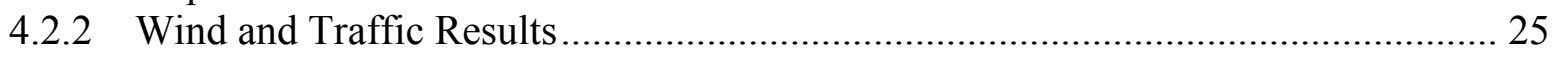

4.2.3 US-26 Channel Results and QUIC Modelinging ..................................................... 32

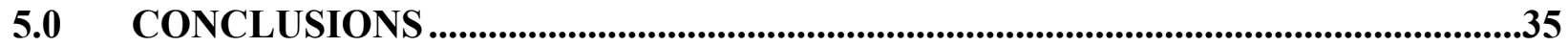

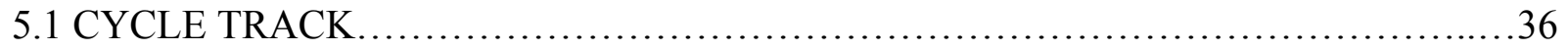

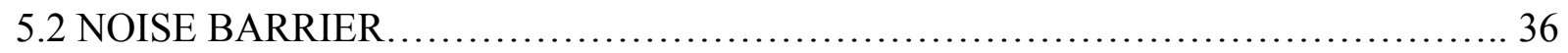

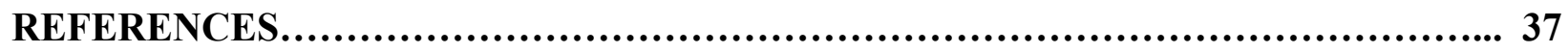




\section{LIST OF TABLES}

Table 1 Mean Number Concentrations, Ranges, Percent Differences, and t-test Results for Bicycle-Lane and Cycle-Track Exposure Concentration Comparisons.................17

Table 2 UFP Concentration Comparisons in particles/cm3 (pt/cc) at One-Second Intervals for US-26 and I-205 Monitoring Locations........................................24

Table 3 Concentration Differences During Varying Wind Directions at I-205................31

\section{LIST OF FIGURES}

Figure 1 Cross-sectional configuration of Southwest Broadway ..........................11

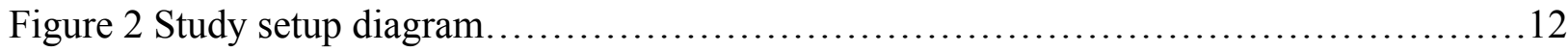

Figure 3 UFP measurement locations along US-26 (a) and I-205 (b)......................14

Figure 4 Images of RM Young Anemometers along study transect.......................15

Figure 5 Feb. 8 Speed averaged over five-minute intervals with a Loess smoothing curve......19

Figure 6 Feb. 8 (a) Traffic flow per five-minute intervals versus time (b) UFP concentrations from driver's side averaged over five-minute intervals versus time (c) UFP concentration differences between bicycle lane and cycle track sides averaged over five-minute intervals versus time. All lines represent Loess smoothing curves.....................20

Figure 7 July 13 (a) Traffic flow per five-minute intervals versus time (b) UFP concentrations from driver's side averaged over five-minute intervals versus time (c) UFP concentration differences between bicycle lane and cycle track sides averaged over five-minute intervals versus time. All lines represent Loess smoothing curves. 21-22

Figure 8 July 13 Speed averaged over five-minute intervals versus time with a Loess smoothing curve.

Figure 9 Ten-minute UFP concentration aggregations in particles/cm3 (pt/cc) with wind and traffic characteristics on (a) March 24 and (b) April 22. $27-28$

Figure 10 Ten-minute UFP concentration aggregations in particles/cm3 (pt/cc) with wind and traffic characteristics on (a) May 13 and (b) May 27 29-30

Figure 11 Study design on US-26 with all three P-Traks within Overlapping Sound Walls......32

Figure 12 Wind field results from QUIC model for US-26 study site.... .33 


\section{EXECUTIVE SUMMARY}

Urban residents spend a considerable amount of time in transportation microenvironments as pedestrians, bicyclists, public transit users, residents and workers situated along roadways, and automobile commuters. Within these microenvironments, vehicles powered by carbon-based fuels (e.g., gasoline, diesel) have a negative impact on air quality. Vehicular exhaust is the source of a multitude of air contaminants, including particulate matter (PM). Particulate matter of concern ranges in size from the largest $\mathrm{PM}_{10}$ (diameter $\left.<10 \mu \mathrm{m}\right)$ and $\mathrm{PM}_{2.5}$ (diameter $<2.5 \mu \mathrm{m}$ ), to microscopic ultrafine particles (UFP). Ultrafine particles have diameters smaller than $0.1 \mu \mathrm{m}$. The majority of UFP present in an urban environment are the result of traffic emissions (Zhang and Morwaska, 2002; Kittelson, 1998; Ristovsk et al., 1998). Significant adverse human health impacts have been connected to UFP number concentrations.

UFP levels that would be experienced by cyclists in roadway environments were used in this study to characterize urban residents' exposure to traffic-related pollution. Additionally, the study focused on the evaluation of mitigation strategies to lower an urban road user's exposure. The first strategy evaluated decreasing proximity of cyclists to motor vehicles in a downtown urban corridor environment, and the second evaluated the use of sound wall barriers as a shielding technique to lower exposure in a freeway/bike facility microenvironment.

The major findings of this research can be summarized as:

- An original method was developed to measure and compare simultaneous UFP exposure for cyclists in a traditional bicycle lane and a cycle track. UFP number concentrations were significantly higher in the typical bicycle lane than the cycle track for all study days, and nearly all study periods within those days.

- A cycle-track roadway design may be more protective for cyclists than a traditional bicycle lane in terms of lowering UFP exposure concentrations. This, of course, must be balanced against other considerations such as vehicle-bicycle conflicts at intersections and other design factors. Based on these initial findings, understanding roadway and traffic effects on exposure levels can help guide bicycle facility design, and pinpoint locations in which mitigation of exposure levels by placement of facilities such as cycle tracks may be most important.

- Using concurrent traffic, wind and air quality measurements, UFP levels were found to be significantly higher along multiuse paths placed in front of noise barriers (on the freeway side) than those behind the noise barriers (on the residential side). The shielding effectiveness of the noise barrier varied by study site and day, but the effectiveness did not appear to relate to traffic or wind conditions. Increased UFP exposures can be partially mitigated by placing the multiuse path on the side of the noise barriers away from freeway traffic. 


\subsection{INTRODUCTION}

Urban residents spend a considerable amount of time in transportation microenvironments as pedestrians, bicycle commuters, public transit users, residents and workers situated along roadways, and commuters within vehicles. Within these transportation microenvironments, vehicles powered by carbon-based fuels (e.g., gasoline, diesel) have a negative impact on air quality. An emerging area of research has shown that human health impacts within transport microenvironments can be considerable, but exposure concentrations and built environment impacts have not been well characterized. As urban public policies increasingly encourage the use of multimodal travel in dense urban centers, mitigation strategies to lower urban residents' exposure to traffic-related pollution need to be assessed.

Vehicular exhaust is the source of a multitude of air contaminants, including particulate matter $(\mathrm{PM})$. Particulate matter of concern ranges in size from the largest $\mathrm{PM}_{10}$ (diameter $<10 \mu \mathrm{m}$ ) and $\mathrm{PM}_{2.5}$ (diameter $<2.5 \mu \mathrm{m}$ ), to microscopic ultrafine particles (UFP). Ultrafine particles have diameters smaller than $0.1 \mu \mathrm{m}$. The majority of ultrafine particles present in an urban environment are the result of traffic emissions (Zhang and Morwaska, 2002; Kittelson, 1998; Ristovsk et al., 1998). Particle number concentrations, which are dominated by ultrafine particles, have been shown to be significantly higher next to a road (Harrison et al., 1999; Junker et al., 2000).

Adverse human health impacts have been connected to ultrafine particle and number concentrations. For a given mass concentration $\left(\mu \mathrm{g} / \mathrm{m}^{3}\right)$, ultrafine particles have $10^{2}$ to $10^{3}$ times higher surface area than fine particles with diameters in the $0.1-2.5 \mu \mathrm{m}$ range, and about $10^{5}$ time more than coarse particles $(2.5-10 \mu \mathrm{m})$ (Harrison et al., 2000). This higher surface area can increase the potential for ultrafine particles to carry toxins into the human body. The small size allows for the deepest deposition of particles into the alveolar region of the lungs, pulmonary interstitial spaces, and possible passage into the circulatory system. It has been shown that these particles accumulate over time in organ tissues (Møller et al., 2008). The deep deposition of these small particles in high numbers can provoke inflammation, which is linked to increased or exacerbated asthma and oxidative stress involved in cardiovascular and pulmonary disease. The presence of a high number of particles in the alveolus has been shown to be more critical to adverse effects and indicative of potential health impacts than total particle mass concentrations (Vinzents et al., 2005; Seaton et al., 1995; Li et al., 2003). The human pulmonary and cardiovascular systems are vulnerable to ultrafine particles.

Due to the sensitivity of the human body to ultrafine particles and the elevated UFP concentrations in and around roadways, ultrafine particle concentrations were used as the focus pollutant of this study to assess mitigation strategies in transportation microenvironments.

Bicyclists and pedestrians, while contributing little to UFP levels in the ambient atmosphere, often find themselves moving within near-road areas with high concentrations of UFP. The road user most often traveling through the highest concentrations of ultrafine particles is the urban cyclist. Elevated levels of ultrafine particles are of concern to bicycle commuters due to the associated health effects and increased respiration and absorption as compared to other road users (McNabola et al., 2007; Van Wijnen et al., 1995; O’Donoghue et al., 2007). Human respiratory tract models using urban exposure concentrations and commute lengths, along with 
breathing parameters and physical/chemical pollutant properties, estimate an overall relative absorption rate up to $38 \%$ higher for cyclists compared to car drivers (McNabola et al., 2008). The increased sensitivity of cyclists and active road users to pollutant exposures led to the selection of bicyclists as the study population to assess mitigation techniques in urban transportation microenvironments.

UFP levels that would be experienced by cyclists in roadway environments were used in this study to characterize urban residents' exposure to traffic-related pollution. Additionally, the study focused on the evaluation of mitigation strategies to lower an urban road user's exposure. The first strategy evaluated decreasing proximity to motor vehicles in a downtown urban corridor environment, and the second evaluated the use of sound wall barriers as a shielding technique to lower exposure in a freeway/bike facility microenvironment.

\subsection{AIR QUALITY AND PROXIMITY TO TRAFFIC STREAM}

Personal exposure studies have shown significantly increased UFP exposure concentrations associated with increased proximity to traffic and volume of traffic (Thai et al., 2008; Boogaard et al., 2009; Kaur et al., 2007; Berghmans et al., 2009; Kaur and Nieuwenhuijsen, 2009). Traditionally, bicycle lanes have been placed adjacent to motor vehicle lanes, especially as urban car commuters and bike commuters are traveling along the same right-of-ways. Recent designs in the U.S have exchanged the locations of parallel parking and bicycle lanes, creating a "cycle track" in which the cyclist is separated by a barrier (the parked cars) from the traffic stream. The barrier formed by the parked cars has the potential to create a perceptibly safer environment, reducing vehicle-bicycle collisions and attracting new riders who may otherwise feel unsafe biking next to moving vehicles. However, the full safety impact of cycle tracks (especially at intersections (Jensen et al.)) has not yet been empirically determined as they are a relatively new facility type (particularly in the U.S.).

While the potential to reduce bicycle-vehicle collisions has been the primary cited benefit of creating a cycle track, this study seeks to determine if cycle tracks can also serve to lower UFP exposure concentrations. Riding in a cycle track can decrease proximity to traffic stream by 1013 feet compared to a typical bicycle lane directly adjacent to the traffic stream, although this range would differ depending on exact cycle-track design and location. The increased distance from the moving vehicles may result in lower UFP concentrations. This study evaluates the effect of increased distance from traffic on pollutant concentrations. We also specifically assess the cycle track as a mitigation strategy that can be implemented in a downtown urban corridor that contains parking lanes without complete separation of cyclists and traffic.

\subsection{BARRIER PLACEMENT}

In urban locations where space is limited, bicycle and pedestrian pathways are often located alongside freeways where uninterrupted right-of-way is available. The microenvironment of the non-motorized pathway directly adjacent to the freeway is a rarely studied location. In such roadway environments, physical barriers or "sound walls" border high-volume roads to reduce 
noise pollution for residential populations nearby. Although designed for noise abatement, roadside barriers may play a role in shielding bicyclists and pedestrians from exposure to vehicle-produced ultrafine particles. Placement of sound walls in between non-motorized pathways and the traffic source (freeway) may have the potential to be more protective of urban active users (cyclists and pedestrians). This study evaluates the use of barriers on pollutant concentrations directly adjacent to the barrier, and assesses the use of sound walls and placement planning to mitigate exposure to pollutants.

\subsection{RESEARCH QUESTIONS}

This study evaluates two different transportation microenvironments to assess traffic-related pollution levels, potential exposure to road users, mitigation techniques to lower pollutant exposure, and the interaction between air quality and transportation parameters. The research focuses on two applicable techniques to understand two mechanisms that could lead to lowered pollutant exposures for urban road users. In particular, the following questions are addressed:

- Can a cycle track serve to lower ultrafine particle exposure concentrations compared to a typical in-road bicycle lane?

- Do sound wall barriers reduce UFP exposure concentrations on an adjacent nonmotorized pathway?

- Does the placement of sound wall barriers affect wind-flow patterns?

- Can traffic data help characterize UFP levels in various transportation microenvironments? 


\subsection{LITERATURE REVIEW}

\subsection{PROXIMITY TO ROADWAY STUDIES}

Personal exposure studies have shown significantly increased UFP exposure concentrations associated with increased proximity to traffic and volume of traffic (Thai et al., 2008; Boogaard et al., 2009; Kaur et al., 2007; Berghmans et al., 2009; Kaur and Nieuwenhuijsen, 2009).

Personal exposure studies in transportation microenvironments tend to focus on the measurement of exposure concentrations of traffic pollutants by different types of road users along various routes. The results tend to be comparisons of concentration levels experienced by a car driver, bus driver, bicyclist, taxi, and sometimes a pedestrian. Only in the past four years have these studies begun to focus on ultrafine particles. A review by Kaur et al. (2007) focusing on fine particulate matter and carbon-monoxide exposure in urban transportation, with a section on ultrafine particles, noted that few cyclist-specific studies have been conducted.

Berghmans et al. (2009) conducted a cyclist-specific study in the town of Mol, near Flanders, Belgium, measuring particle concentrations for cyclists as they traveled along a route near the city center with various levels of vehicular traffic. Higher UFP concentration levels were found when traveling on roads with higher traffic volumes, traffic congestion, and during morning and evening rush hours. A cyclist-specific study in Vancouver, B.C., measured particle concentrations as a cyclist moved through areas with different land uses. Thai et al. (2008) found the highest UFP concentrations associated with heavy traffic volumes and along routes where the cyclist was in close proximity to motor vehicles. For example, the highest UFP levels occurred on Burrard Street, where the bicycle lane was in the middle of the road with two lanes of traffic to the left and one to the right; a downtown road classified as a highway with designated bike lanes on each side; and Burrard Bridge, a major transit corridor. Boogaard et al. (2009) assessed cyclist and car-driver exposure on routes within 11 Dutch cities. Through gathering data on the type of road, passing vehicle and type of traffic, Boogaard et al. attempted to quantify determinants in UFP concentration variability. Traveling on bicycle lanes and paths close to motorized traffic was a significant predictor affecting UFP number concentration, along with passing vehicles (mopeds especially), waiting for traffic lights, and passing large intersections. Not only does large traffic volume have an association to UFP levels in personal exposure studies, but roadway type and proximity to the traffic stream do as well.

\subsubsection{Extent of Traffic Data Used in Personal Exposure Studies}

The quantification of UFP concentration variability while traveling on a bicycle or car (Boogaard et al., 2009) was one of the more extensive personal exposure studies, especially in terms of transportation data. No real-time traffic counts were performed alongside the particle measurements, but instead annual average, 24-hour, traffic-intensity data available for five cities was used and volumes were assigned for various streets. Road type consisted of 14 classes which detail whether the road has a bicycle path, cyclists would be waiting for a traffic light or roundabout, and so on. Intersections were defined as normal or large depending on the number of lanes. The passing of motorized vehicles was only recorded when an obstruction occurred, which was defined by the two sample cyclists having to cycle single file rather than next to each other. This is an example of the most extensive use of transportation data combined with air quality measurements. Another study in which UFP exposure concentrations for various travel modes 
were collected (Kaur et al., 2005) was followed by an investigation into the determinants of exposures (traffic counts, meteorological variables and transportation mode) using a regression technique (Kaur et al., 2009). Even this more in-depth analysis of exposure concentrations and possible variables of cause and effect did not use real-time collected traffic data. Post-processed traffic-flow data collected by the split, cycle and offset optimization technique (SCOOT) was the transportation data used in the regression analysis. While traffic count was a statistically significant determinant of UFP concentrations, the authors noted the limitation of having traffic count as the only measure to determine influence of traffic on exposure levels, plus the variability in the traffic counts used was low. Idle times, traffic flow, traffic density and composition may be better measures.

Traffic data used in studies concerning road users' exposure to ultrafine particles typically do not incorporate real-time data, but instead use counts from an area not specific to the study location. In addition, time of day and morning and evening peaks are used as proxies for associations with traffic and pollutant levels. Collecting real-time traffic-count data, composition and flow should provide a valuable understanding to transportation microenvironments and how mitigation strategies to lower exposures are related.

\subsection{BARRIER STUDIES}

Due to their height and impenetrability, physical barriers alongside roadways - such as dense vegetation, buildings and other structures - have significant impacts on localized airflow, creating complex dispersion patterns for airborne pollutants (Bowker et al., 2007; Hagler et al., 2009; Finn et al., 2009). The noise barrier is a prominent and common barrier in urban areas with dense populations near roadways. Noise barriers along high-volume roadways are constructed exclusively for the abatement of vehicle-generated noise (Klingner et al., 2003). The height of the barrier depends on sound-level mitigation requirements. By blocking the line of sight between an individual and the road, sounds levels are decreased by $5 \mathrm{~dB}$ (Klingner et al., 2003). Each additional meter of barrier height decreases the sound level by $1.5 \mathrm{~dB}$, with the objective to reduce freeway sound levels by $10 \mathrm{~dB}$ for households immediately behind the sound wall (Klingner et al., 2003).

Studies concerning air quality and the effects of sound wall barriers have focused on the longrange dispersion of pollutants. Bowker et al. (2007) examined the effects of noise barriers, trees and buildings on the flow patterns and transport of pollutants from a freeway in Raleigh, N.C. The effects were analyzed with UFP measurements and model outputs using the Quick Urban and Industrial Complex (QUIC) model, which is empirically based and simulates fine-scale wind field and dispersion patterns around obstacles (Bowker et al., 2007). Their findings showed noise or roadside barriers affected pollutant flow patterns three ways: (1) The plume moved up and over the noise barrier like an elevated source; (2) a recirculation wake region formed in the lee of the barrier; and (3) if the elevated plume encountered other obstacles such as trees or buildings, increased mixing occurred which could lead to decreased pollutant concentrations. With the first scenario found by Bowker et al., higher concentrations of pollutants would reach locations further downwind than compared with a no-barrier situation. Other studies have also found the pattern of a recirculation cavity forming behind the barrier wall when winds blow perpendicular to the barrier (Hagler et al., 2009; Lidman et al., 1985). In such situations, some studies have shown pollution concentrations between $0 \%$ and $80 \%$ of roadside values for distances between 
three and 12 wall heights downwind $(24,25)$. The dispersion and shielding effects of noise barriers for locations immediately adjacent to the wall have not been measured.

\subsubsection{Importance of Wind Fields}

Wind and flow patterns over and around noise barrier walls along freeways are key in understanding pollutant concentrations found in these transportation microenvironments. As in the previous studies, a perpendicular wind may form a recirculating vortex behind the wall, but other wind conditions and configurations of noise barrier walls have not been investigated. The QUIC model tool from the Los Alamos National Laboratory/University of Utah used in Bowker et al. is specifically designed to generate airflow patterns and dispersion around obstacles on an urban scale. The model predicts velocities and concentrations at uniformly spaced grid cells throughout a complex, three-dimensional domain of interest. The predictions are time averaged and represent steady state conditions. The QUIC model was used in the current study to understand wind patterns around edges of noise wall barriers and the noise barrier configuration at the US-26 site. 


\subsection{METHODOLOGY}

\subsection{CYCLE TRACK STUDY DESIGN}

Measurements for this study were conducted on Southwest Broadway, a multilane, one-way southbound street in downtown Portland near the Portland State University campus. The road is used by bicyclists, cars, trucks and buses. Traffic composition and volumes vary at this location throughout the day. Note that there is only one four-leg intersection on this cycle track; all others are three-leg since Broadway is adjacent to campus.

Prior to implementation of the cycle-track design, the cross section consisted of three lanes with a traditional bicycle lane located between the right-most travel lane and a row of curb parking (see Figure 1 (a)). After cycle-track installation two travel lanes remained, with an offset row of parallel parking providing a buffer to the cycle track, approximately 10-11 feet in width (see Figure 1(b)). The arrow in Figure 1(b) points to the cycle track. The curb-to-curb distance was maintained during reconfiguration, requiring only lane re-striping, appropriate pavement markings, and new signage.

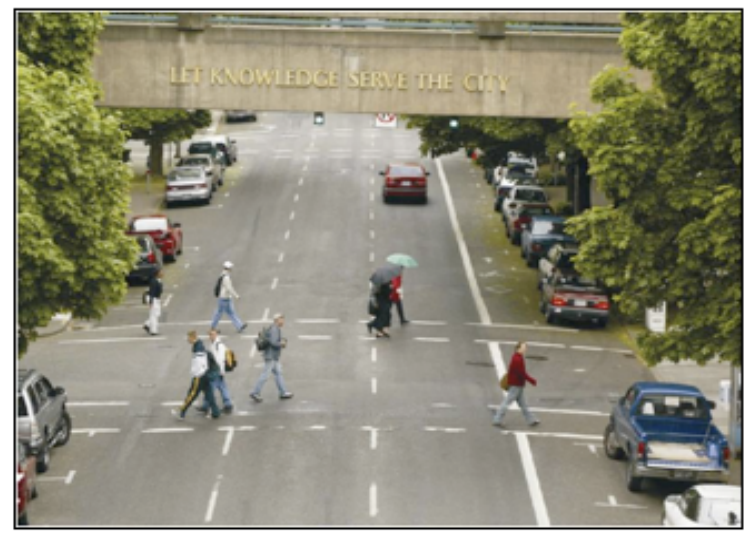

View of SW Broadway before cycle track

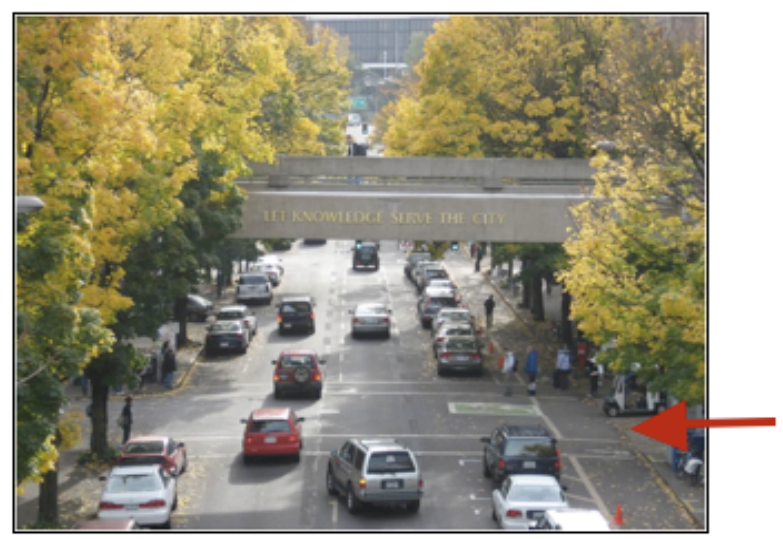

View of SW Broadway with cycle track

(a)

(b)

Figure 1 Cross-sectional configuration of Southwest Broadway (a) prior to cycle track and (b) with cycle track implementation.

After implementation of the cycle track, monitoring equipment was set up at a mid-block location, north of the intersection with Southwest Harrison Street (Figure 2). Particle number concentrations and traffic measurements were made over four days in the span of several months with different combinations of equipment and study durations depending on the availability of equipment and personnel. On each study day, two P-Trak ultrafine particle counters (TSI Model 8525 ) were placed in a parked car in the parallel parking (buffer) zone on the west side adjacent to the cycle track. P-Trak instruments are commonly used in personal exposure studies of UFP for cyclists and other transportation modes because of portability and technological advances to measure number concentrations. Number concentrations in ambient air are dominated by ultrafine particles. In comparable studies and personal exposure studies using the P-Trak instrument, particle number concentrations and ultrafine particles are used interchangeably. Prior 
to data collection, a run of the P-Trak instruments (recently factory calibrated) side by side in the laboratory for three and a half hours ensured the instruments correlated $\left(r^{2}=0.996\right)$.

The parked car was utilized in a novel method to compare simultaneous measurements of exposure concentrations that would be experienced in a conventional bicycle lane versus a cycletrack lane. The sensors were placed on the front seats of the car with the collection tube running out the windows, taped to the side-view mirrors (Figure 3). Measuring exposure on the driver's side of a car parked within this offset parking lane is representative of the exposure concentration in a traditional bicycle lane; exposure measured on the passenger-side represents the cycle track exposure concentration. The driver's side measurements are in the location and proximity to traffic where a bicycle lane would typically be marked and will be referred to as the bicycle lane results. The passenger-side measurements are located a few feet from the cycle track due to the white-striped buffer area. The passenger-side measurements are the upward limit for cycle-track exposure concentrations due to the passenger-side-view mirror location and width of the cycle track. The cycle-track UFP concentrations would range lower towards the sidewalk. Exposure concentration is a typical variable used in personal exposure studies to understand potential health impacts on humans in urban transportation microenvironments. Total or in-traffic exposure is the product of exposure concentration, exposure duration and breathing rate.

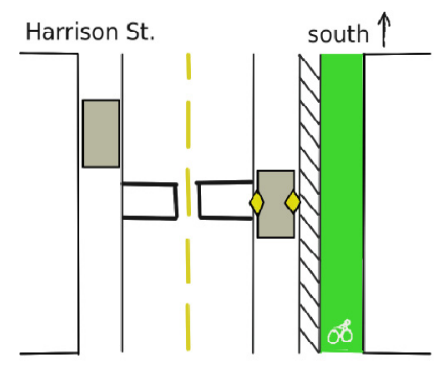

Figure 2 Study setup diagram. Green lane represents cycle track. Gray boxes represent cars. Yellow diamonds represent P-Trak instruments. Black lines in traffic lanes represent traffic counters.

All ultrafine particle counts were made at a one-second resolution. The P-Trak instrument measures particle number concentrations using condensation with isopropyl alcohol and an optical sensor. Particle number concentrations are obtained for particles in the size range of 0.02$1 \mu \mathrm{m}$. The particle counts measured by this instrument are dominated by the UFP size range. The maximum concentration level measured by this equipment is $500,000 \mathrm{pt} / \mathrm{cc}$.

Four different experimental setups were conducted, each described according to the study date and time periods in the following paragraphs. The first study design with P-Traks only was implemented on Nov. 24, 2009. Measurements at the first location began at 5:45 a.m.and continued until 10:45 a.m. Particle exposure concentrations were measured in a second parking space from 10:58 a.m. to 1:52 p.m., and in a third parking space from 2:05-4:51 p.m. City blocks in Portland tend to be shorter than in most U.S. cities. In all cases, the distance between P-Trak locations along Broadway did not exceed 50 feet.

Data collection on Feb. 8, 2010, occurred in the same parking space at the mid-block location from 5:31-10:49 a.m. Traffic data were also collected during this time period using MetroCount 
5600 traffic tubes counters. The traffic counting tubes were placed in the right-most lane next to the vehicle containing the P-Traks, and collected individual vehicle records consisting of passage time, vehicle classification (based on length estimates), and speed.

Data collection on June 7, 2010, occurred in the same mid-block location as the Nov. 24 and Feb. 8 study days. Particle measurements occurred from 6:53 a.m. to 2:20 p.m. Additionally, a third P-Trak was placed on the edge of the sidewalk closest to the cycle track in the same transect as the car P-Traks from 7:54 a.m. to 2:20 p.m. Traffic tubes were placed across both lanes beginning at 5 a.m. and traffic data were collected throughout the entire particle measurement period. The heights of the P-Trak inlet tubes were maintained at the same elevation across the entire study period.

The final day of data collection occurred on July 13, 2010, from 7:25 a.m. to 9:42 p.m. Particle measurements were made on the driver and passenger-sides of the study vehicle in the mid-block location. In this setup, traffic data were collected with traffic tube counters across both travel lanes.

\subsection{PASSIVE SHIELDING WITH NOISE BARRIERS STUDY DESIGN}

\subsubsection{Description of Sampling Sites}

UFP levels were measured near two freeways in Portland. Study sites were chosen based on proximity of noise barriers to traffic, absence of other significant UFP sources in the surrounding area, presence of bicycle/pedestrian facilities, geography surrounding the site, and orientation of the roadway to prevailing wind conditions. To facilitate comparison between the two locations, noise barriers located at both sites share similar geography; both are roughly 15 feet high and one foot thick, though dimensions vary somewhat with local geography.

Site 1: US-26, Figure 3a; a nine-lane (five eastbound, four westbound) freeway west of the city center. At the monitoring site, two noise barriers overlap for roughly 95 feet and the bicycle/pedestrian path passes through the overlap section. The study site directly abuts eastbound vehicle lanes. There is no median; travel directions are separated by Jersey barriers. Land on the south side of the barriers is flat and largely paved, with a parking lot and sparse vegetation. The speed limit is 55mph. The road grade is negligible. Morning peak-period flows toward the city center are eastbound (near side), while evening peak flows are westbound. Both peak periods experience recurring congestion in this area.

Site 2: Interstate 205, Figure 3b; an eight-lane (four northbound, four southbound) beltway east of the city center. The bicycle/pedestrian path runs along the west side right-of-way, separated from the road by a single noise barrier for a portion of its length at the monitoring site. The remaining length of pathway is not separated from the freeway by any substantial barrier. Portland's MAX light rail, on a 50-foot-wide alignment, runs between the bicycle/pedestrian pathway and the freeway. Vehicle directions are separated by a 70-foot median, placing northbound traffic on a slight elevation rise compared to southbound traffic. Residential development on the west side of the freeway is set back from the noise barrier and pathway by a row of trees and small vegetation. The speed limit is $55 \mathrm{mph}$. The road grade is negligible. The site experiences afternoon peak-period congestion in the northbound direction. 


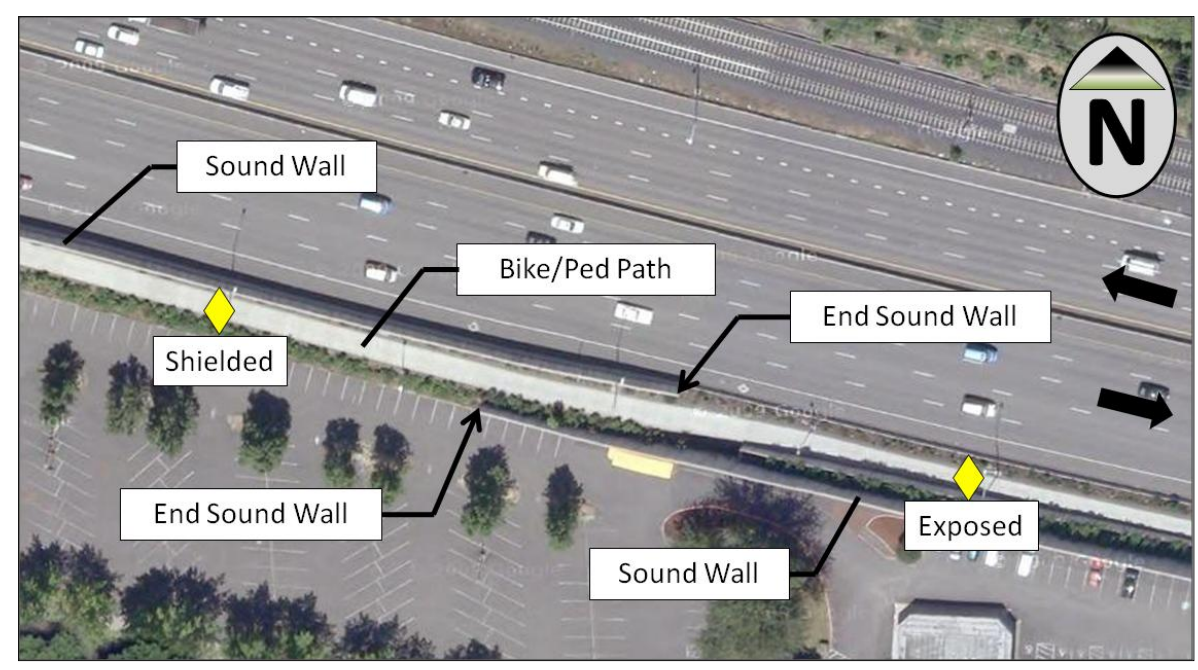

(a)

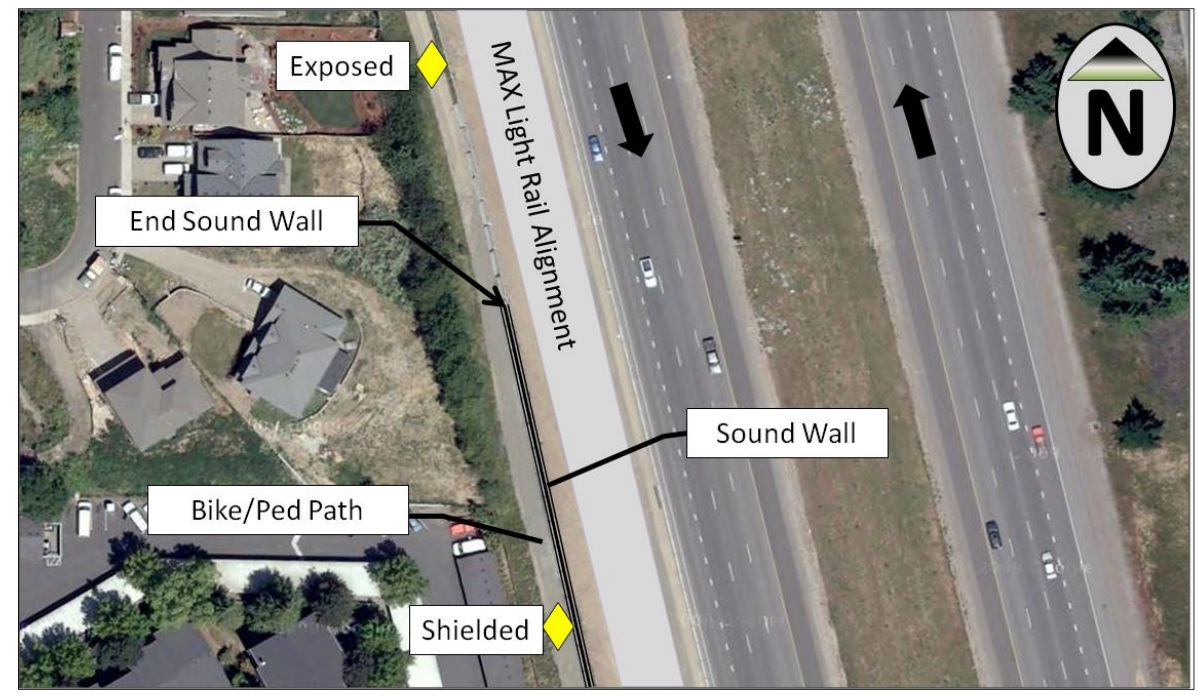

(b)

Figure 3 UFP measurement locations along US-26 (a) and I-205 (b). Diamonds indicate sampling positions. (Image from www.maps.google.com) 


\subsubsection{Sampling and Instrumentation}

Field sampling was conducted at the US-26 site on March 24, April 22, and May 13, 2010, and at the I-205 site on May 27, 2010. Both roadways were sampled during weekdays from approximately 7 a.m. until late morning (between 11 a.m. and noon).

UFP concentrations were measured using TSI P-Trak Ultrafine Particle Counters (TSI Model 8525) (see description of equipment in section 3.1 above). The devices were mounted with intake points approximately at breathing level along the side of the bicycle/pedestrian paths, in the locations shown in Figure 3 as "Exposed" and "Shielded." The P-Trak marked as "Exposed" in Figure 3 was placed in front of the noise barrier or in a location where no noise barrier is present to gather unshielded concentration levels. The air was open to the freeway. Another P-Trak, marked "Shielded," was placed behind the noise barriers to gather concentration levels influenced by the noise barrier's presence. The noise barrier was in between the P-Trak and the pollution source.

Wind speed and direction were measured using up to three RM Young Wind Anemometers (Young Model SE), placed at fixed intervals along the bicycle/pedestrian path and adjacent to the P-Traks (see Figure 4). Localized wind measurements were taken to understand wind movement across the roadways and within and around the sound walls. The wind speed sensor has an accuracy of $\pm 0.3 \mathrm{~m} / \mathrm{s}$ or $1 \%$ of the reading, whichever is greater. The wind direction sensor has an accuracy of $\pm 0.2^{\circ}$.

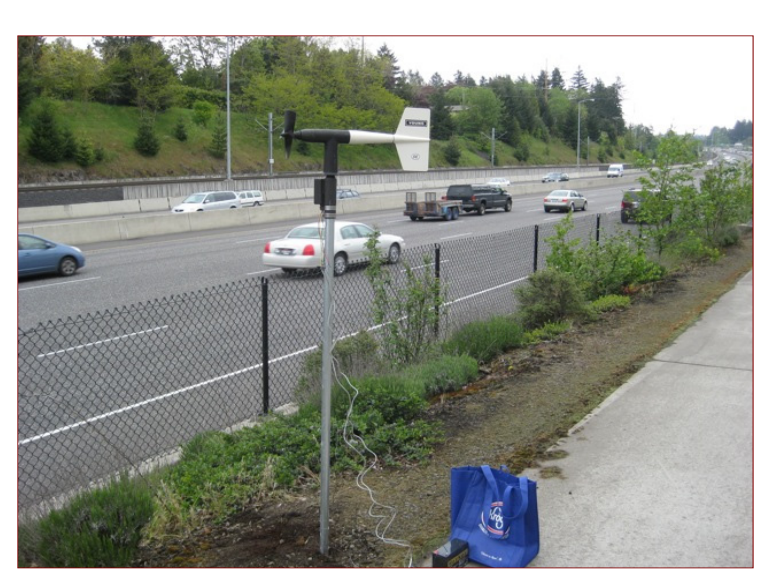

(a)

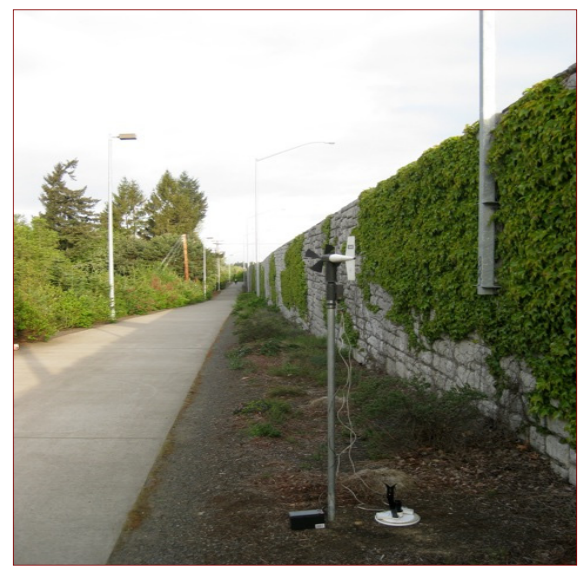

(b)

Figure 4 Images of RM Young Anemometers along study transect at locations with (a) no sound wall present and (b) sound wall present.

Continuous vehicle counts were obtained from the Portland Oregon Regional Transportation Archive Listing (PORTAL- at www.portal2.its.pdx.edu), an archive of transportation data including freeway loop detector data from the Portland-Vancouver metropolitan region, as well as weather, incident, transit, freight, and other data. Dual-loop detectors collecting volume, speed and land occupancy at 20-second aggregations are located throughout the freeway system in the region. For this study, the closest loop detector stations to the monitoring site were used for data 
collection. Loop-detector data were gathered for the vehicle travel directions closest to the monitoring site: eastbound and southbound traffic for the US-26 and I-205 sites, respectively. At the US-26 site, the loop-detector station is located 1,400 feet upstream of the monitoring site. The loop detector at the I-205 site is approximately 4,750 feet upstream. The loop detectors are located immediately upstream of freeway on-ramps, so both sites have a lane merge intervening between air quality/wind measurements and traffic measurements. 


\subsection{RESULTS}

\subsection{CYCLE TRACK STUDY}

\subsubsection{Exposure Concentrations}

Table 1 contains median and mean concentration values and ranges of exposure concentrations for the driver's side (traditional bicycle lane) and passenger's side (cycle-track lane) positions for all study days.

Table 1 Mean Number Concentrations, Ranges, Percent Differences, and t-test Results for Bicycle-Lane and CycleTrack Exposure Concentration Comparisons

\begin{tabular}{|c|c|c|c|c|c|c|c|c|c|c|c|}
\hline \multirow[b]{2}{*}{ Date } & \multirow[b]{2}{*}{ Time } & \multicolumn{3}{|c|}{ Bicycle Lane } & \multicolumn{3}{|c|}{ Cycle Track } & \multirow[b]{2}{*}{$\begin{array}{l}\text { Mean } \\
\text { Diff. } \\
\text { ( pt/cc) }\end{array}$} & \multirow[b]{2}{*}{$\frac{\mathscr{O}}{\underline{\pi}}$} & \multirow[b]{2}{*}{ 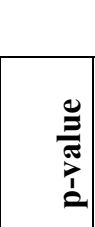 } & \multirow[b]{2}{*}{$\begin{array}{l}\text { \% } \\
\text { Diff }\end{array}$} \\
\hline & & $\begin{array}{l}\text { Median } \\
\text { (pt/cc) }\end{array}$ & $\begin{array}{l}\text { Mean } \\
\text { Conc } \\
\text { (pt/cc) }\end{array}$ & $\begin{array}{l}\text { Range } \\
(\mathrm{pt} / \mathrm{cc})\end{array}$ & $\begin{array}{l}\text { Median } \\
\text { (pt/cc) }\end{array}$ & $\begin{array}{l}\text { Mean } \\
\text { Conc } \\
\text { (pt/cc) }\end{array}$ & $\begin{array}{l}\text { Range } \\
(\mathbf{p t} / \mathbf{c c})\end{array}$ & & & & \\
\hline $\begin{array}{l}\text { Nov24, } \\
2009\end{array}$ & $\begin{array}{l}5: 45- \\
10: 45 \text { AM }\end{array}$ & 31,400 & 43,788 & $\begin{array}{l}14,500- \\
500,000\end{array}$ & 30,500 & 37,498 & $\begin{array}{l}15,000- \\
365,000\end{array}$ & 6,125 & 19.6 & $<0.01$ & 15 \\
\hline $\begin{array}{l}\text { Nov24, } \\
2009 \\
\end{array}$ & \begin{tabular}{|l|l}
$10: 58$ AM \\
$-1: 52$ PM \\
\end{tabular} & 28,200 & 56,845 & $\begin{array}{l}4,510- \\
500,000\end{array}$ & 26,000 & 35,802 & $\begin{array}{l}13,600- \\
500,000\end{array}$ & 21,043 & 28.8 & $<0.01$ & 38 \\
\hline $\begin{array}{l}\text { Nov24, } \\
2009\end{array}$ & $\begin{array}{l}2: 05 \\
-4: 51 \text { PM } \\
\end{array}$ & 25,400 & 37,476 & \begin{tabular}{|l|}
$9,980-$ \\
500,000
\end{tabular} & 20,600 & 24,618 & \begin{tabular}{|l|}
$2,230-$ \\
312,000
\end{tabular} & 12,589 & 29.2 & $<0.01$ & 35 \\
\hline $\begin{array}{l}\text { Feb 8, } \\
2010\end{array}$ & \begin{tabular}{|l|}
$5: 31$ \\
$-10: 49 A M$
\end{tabular} & 30,600 & 47,601 & $\begin{array}{l}12,300- \\
500,000\end{array}$ & 29,500 & 44,245 & $\begin{array}{l}3,340- \\
500,000\end{array}$ & 3,309 & 10.3 & $<0.01$ & 8 \\
\hline $\begin{array}{l}\text { June } 7, \\
2010\end{array}$ & $\begin{array}{l}6: 53 \text { AM } \\
-2: 20 \text { PM }\end{array}$ & 14,700 & 25,271 & $\begin{array}{l}3,340- \\
500,00\end{array}$ & 14,200 & 20,805 & $\begin{array}{l}5,750- \\
500,000\end{array}$ & 4,465 & 20.9 & $<0.01$ & 18 \\
\hline $\begin{array}{l}\text { July 13, } \\
2010\end{array}$ & \begin{tabular}{|l}
$7: 24$ AM \\
$-9: 42$ PM
\end{tabular} & 8,290 & 13,839 & $\begin{array}{l}2,390- \\
500,000\end{array}$ & 7,660 & 10,558 & $\begin{array}{l}5,620- \\
500,000\end{array}$ & 3,309 & 10.3 & $<0.01$ & 24 \\
\hline
\end{tabular}

One-sided, paired t-tests were used to evaluate if the driver-side exposure concentrations were greater than the passenger-side exposure concentrations. T-test results and percent differences are shown in Table 1. Using a significance level of a $\mathrm{p}$-value $=0.05$, exposure concentrations were significantly greater on the driver side representing the typical bicycle lane compared to the passenger side representing the cycle track for all study days. The one-second sampling interval captures very quick changes and short-term peak exposures, explaining the wide range of particle number concentrations for the bicycle lane and cycle track positions. The cycle track has the potential to lower ultrafine exposure concentrations compared to a traditional bicycle lane.

While the bicycle-lane exposure concentrations were always significantly greater than the cycletrack exposure levels, there was a wide range in the mean of the differences and percent differences ( $8 \%-38 \%$ ) (see Table 1). The greatest difference (38\%) between the bicycle lane and cycle track occurred for the second parking space from 10:58 a.m. to 1:52 p.m. on Nov. 24. The next greatest difference (35\%) occurred on the same day in the third space from 2:05-4:51 p.m. The time periods with the greatest percent differences between the two bicycle-facility designs 
overlap with time periods of high traffic volumes for Southwest Broadway. The smallest difference (8\%) occurred on Feb. 8, 2010, from 5:31-10:49 a.m. The low volume of traffic in the first hour and a half of this study period would lead to less total UFP emissions and hence the smallest difference for the bicycle-lane and cycle-track measurements.

Particle number distributions showed bicycle-lane measurements greater than 300,000 $500,000 \mathrm{pt} / \mathrm{cc}$ occurred more frequently compared to cycle-track measurements. The inability of the equipment to capture peaks greater than 500,000pt/cc may have caused mean differences to be underestimated. These data suggest less peak exposure concentrations occur on the cycle track compared to a conventional bicycle lane since the cycle-track measurements are the upper limit (due to cross-sectional location).

Not included in Table 1 are the results for the sidewalk measurements on June 7. The sidewalk median exposure concentration was equal to $12,900 \mathrm{pt} / \mathrm{cc}$ with a mean concentration of $15,535 \mathrm{pt} / \mathrm{cc}$ and a range from $6,890-433,000 \mathrm{pt} / \mathrm{cc}$. The bicycle-lane concentrations were significantly greater than the sidewalk with a mean difference equal to $6,805 \mathrm{pt} / \mathrm{cc}$, $\mathrm{t}$-value $=28.4$, p-value $<0.01$. The percent difference was $38 \%$. The cycle-track concentrations were also significantly greater than the sidewalk with a mean difference equal to $2,157 \mathrm{pt} / \mathrm{cc}$, $\mathrm{t}$-value $=20.5$, p-value $<0.01$. The percent difference for the cycle track and sidewalk was $25 \%$.

The differences in the UFP levels for the typical bicycle lane and cycle track are most likely due to the increased horizontal distance from the traffic stream and the airflow over the parked vehicle. Over this distance ultrafine particles coagulate (21) and grow to larger, potentially less harmful particles. It is unlikely that the parked cars act as a physical barrier for the ultrafine particles, in which particles collide with car surfaces and adhere to them. Ultrafine particles behave as a gas and this explanation would relate more appropriately to larger particles with greater mass. However, future studies will test dry deposition of ultrafine particles for the possibility of additional explanation. The possibility of a traffic-pollution "shadow" on the passenger side of the car where the cycle-track collection tube intake was located will be evaluated in future work using a computational fluid dynamic model to generate wind fields.

The continued significant decline in exposure concentrations from bicycle lane to cycle track to sidewalk also shows a strong likelihood of horizontal distance being the mechanism for the exposure level differences. An assessment of pedestrian exposure to air pollutants along a major road in central London, UK, found UFP number counts to be significantly higher when walking along the curbside edge of the sidewalk compared to the building side (22). The width of the sidewalk is comparable to the width of the parking lane and buffer zone placed between the cycling lane and motor vehicles in the cycle-track design.

\subsubsection{Comparison with Measured Traffic}

Traffic data were collected for five hours and 20 minutes (5:31-10:49 a.m.) on Feb. 8 during particulate matter collections. Traffic volume for the right-most travel lane during this period 
was 1,086 vehicles or $204 \mathrm{veh} / \mathrm{hr} / \mathrm{lane}$. Speeds for vehicles in this lane ranged from $6.40 \mathrm{mph}$ to $54 \mathrm{mph}$ with a time mean value of $30.11 \mathrm{mph}$ (Figure 5). Traffic composition was not analyzed in this paper.

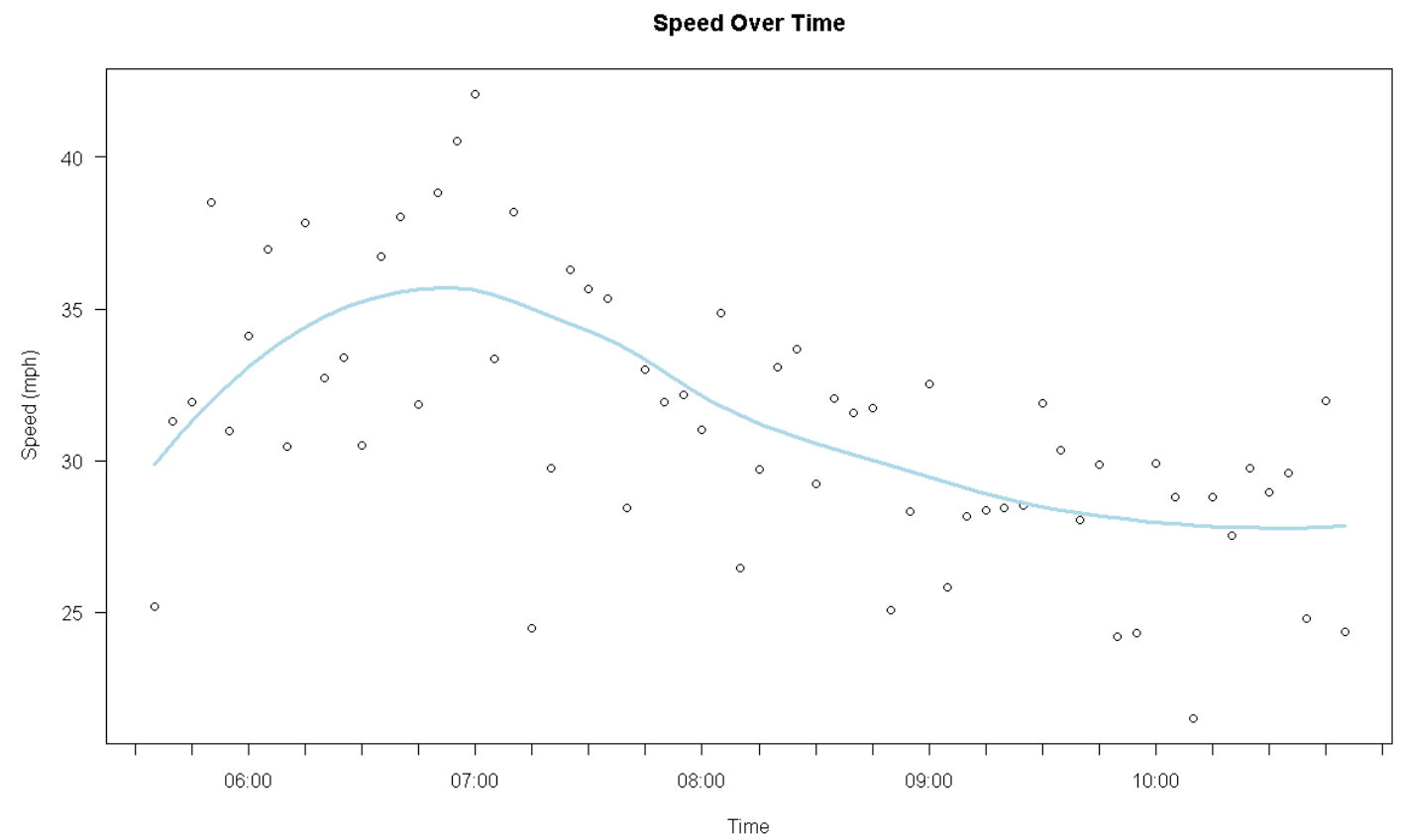

Figure 5 Feb. 8 Speed averaged over five-minute intervals with a Loess smoothing curve.

Traffic increased throughout the morning peak period (with a maximum near 8:30 a.m.), then remained relatively constant throughout the remaining time (Figure 6(a)). The steeper increase in traffic flow up until 8:15 a.m., followed by stabilization of the mean and greater variability in traffic flow, may be due to the intersection reaching capacity or a change in intersection signalization timing as the morning progressed. UFP number concentrations from the driver's side P-Trak averaged at five-minute intervals also show an increase up to a peak in a Loess smoothing curve around approximately 8:15 a.m. (Figure 6(b)). Exposure concentration differences between the bicycle lane and cycle track show a peak around 8:40-8:45 a.m. (Figure 6(c)). 
(a)

Traffic Flow Over Time

(b)
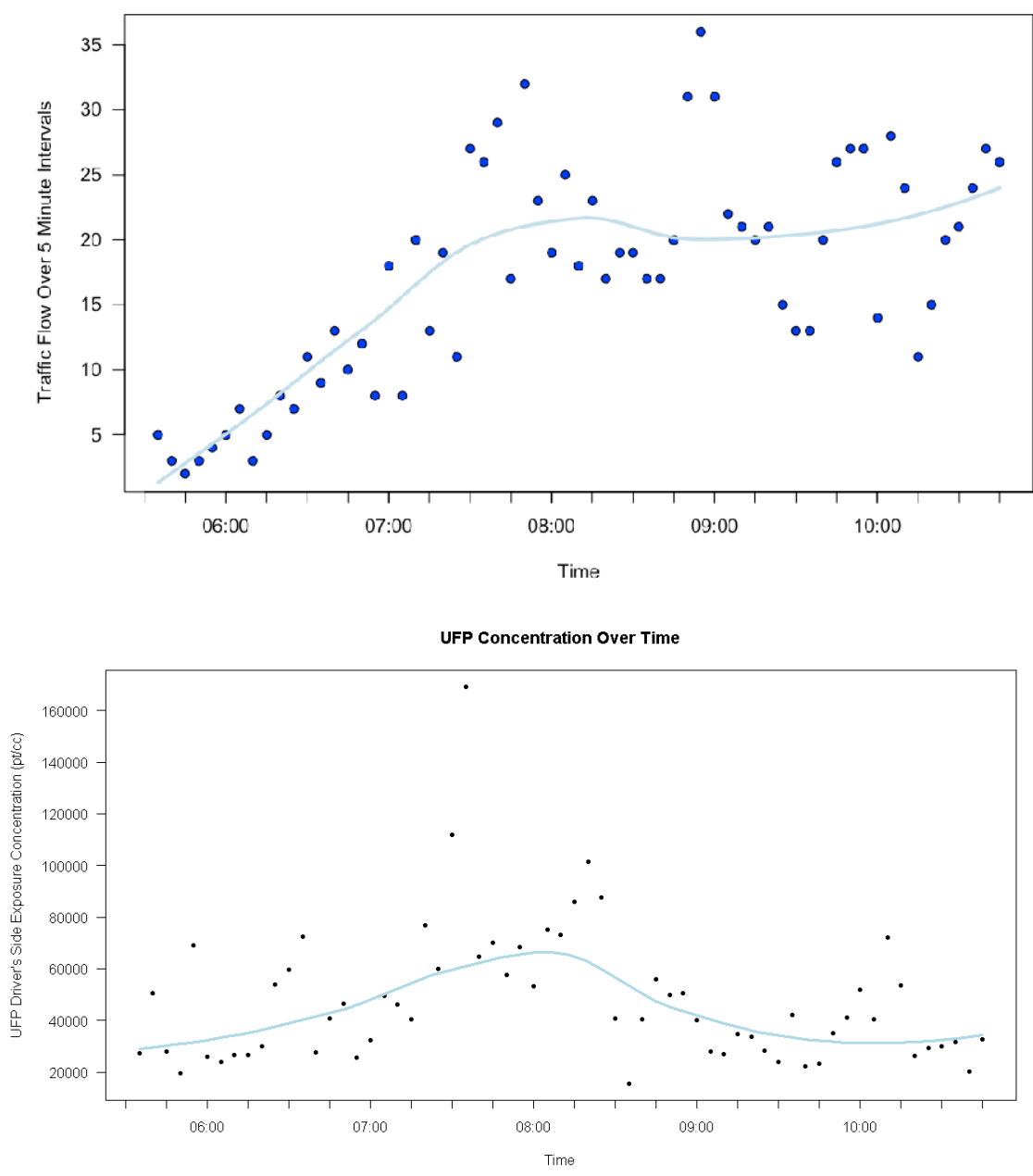

(c)

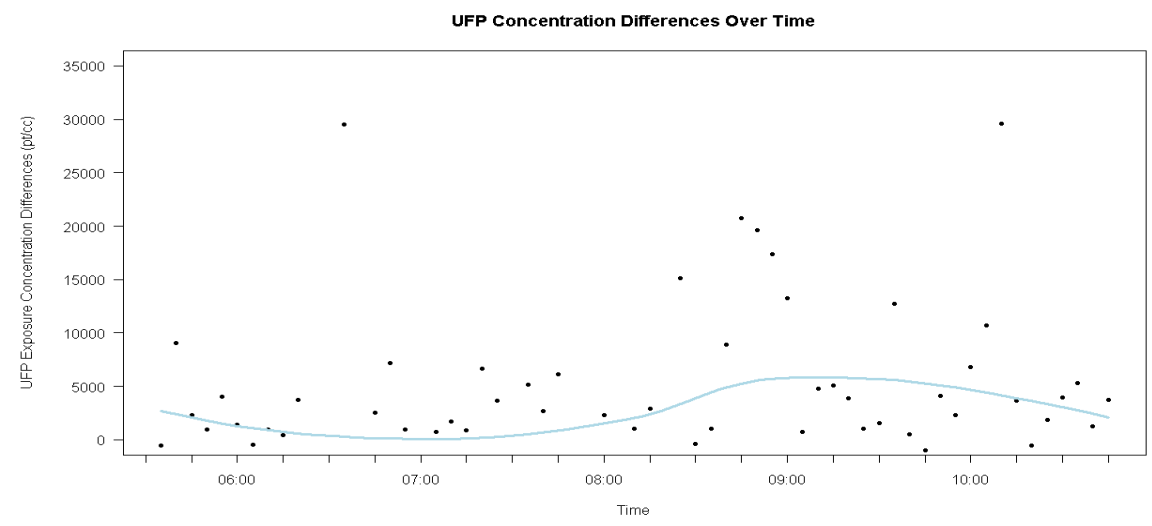

Figure 6 Feb. 8 (a) Traffic flow per five-minute intervals versus time (b) UFP concentrations from driver's side averaged over five-minute intervals versus time (c) UFP concentration differences between bicycle lane and cycle track sides averaged over five-minute intervals versus time. All lines represent Loess smoothing curves.

Traffic data obtained on June 7 were invalid due to a data collection error. Traffic data for July 13 were collected for approximately 14 hours, including the morning and evening periods. The 
total traffic count from 7:25 a.m. to 9:42 p.m. across both lanes was 8,232 vehicles or $294 \mathrm{veh} / \mathrm{hr} / \mathrm{ln}$.

Traffic increased relatively linearly from 10:15 a.m. until a peak around 4:15 p.m. as shown by a Loess smoothing curve in Figure 7(a). Traffic declined through the rest of the evening until the tubes were disconnected. Ultrafine particle concentrations from the driver's side averaged over a five-minute interval show an increase up to a point around noon (Figure 7(b)). Figure 6b shows the variability or range of the UFP exposure concentrations around the Loess curve to be greater during the early and middle parts of the day compared to the end of the day when traffic volumes were decreasing. Exposure concentration differences also show a peak at noon (Figure 7(c)).

The traffic flow peak around 4 p.m. on July 13 was not matched by a peak in UFP, which were declining from a peak around mid-day (Figure 7a) and (b)) suggesting the data may be missing an important correlate such as wind parameters. Future work with radar and video to capture traffic composition and the use of three-dimensional ultrasonic anemometers that measure vertical and horizontal wind fluxes will allow for further exploration into such effects.

(a)
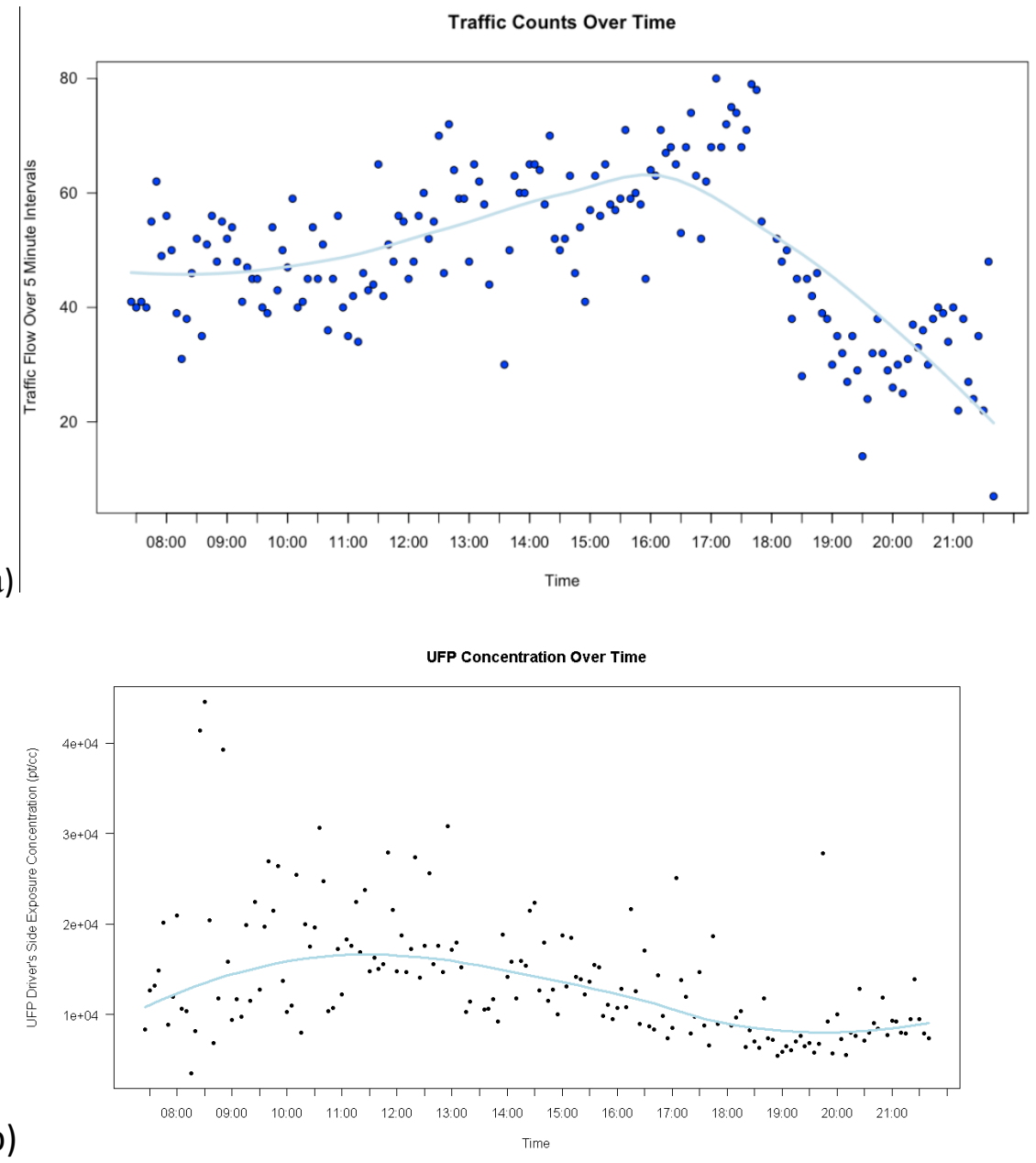


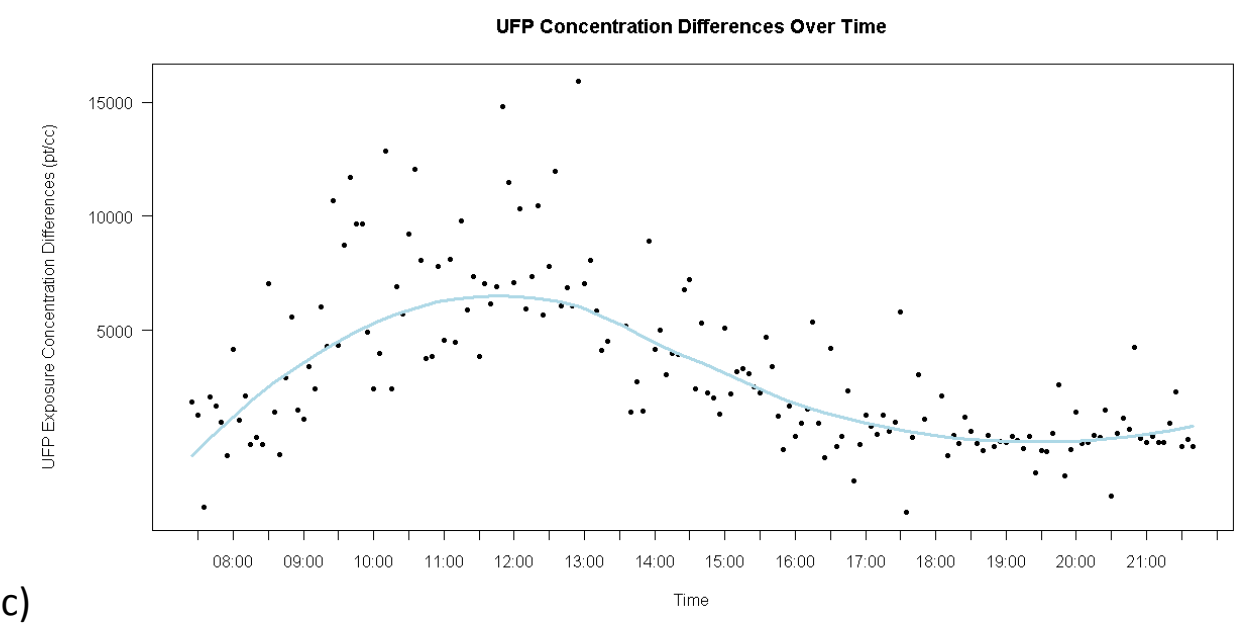

Figure 7 July 13 (a) Traffic flow per five-minute intervals versus time (b) UFP concentrations from driver's side averaged over five-minute intervals versus time (c) UFP concentration differences between bicycle lane and cycle track sides averaged over five-minute intervals versus time. All lines represent Loess smoothing curves.

On July 13th, the time mean speed of vehicles in the right-most motor vehicle travel lane (adjacent to research vehicle) was $28.34 \mathrm{mph}$, with a range from $1.20 \mathrm{mph}$ to $53 \mathrm{mph}$. The leftmost travel lane (furthest from the cycle track and study vehicle) had a time mean speed of 25.83 mph with a range from 5.70 to $56.50 \mathrm{mph}$. Both lanes together averaged $27.62 \mathrm{mph}$, with a range from 11 to $44.80 \mathrm{mph}$.

The averaged speeds over five-minute intervals of vehicles in both lanes did not fluctuate much through the day, with the Loess smoothing curve not deviating far from the range of $25 \mathrm{mph}$ to $32 \mathrm{mph}$ (Figure 8). The decreasing trend in speed in the morning from 7:30-11 a.m. seen on Feb. 8 was also seen on July 13 (Figure 6 and 7). This trend continued on July 13 until the median speed dipped to about 25mph from 1:30-2:30 p.m. Speed began to increase linearly at about 5 p.m. on July 13. Traffic counts peaked around 4:15 p.m., so the time periods with fewer cars on the road followed the slight increase in car speeds.

The placement of the study vehicle from 10:58 a.m. to 1:52 p.m. on Nov. 24 was different than the mid-block location just north of Southwest Harrison used on all other study days. For this time $\mathrm{p}$ riod, the vehicle was at the front parking spot closest to the traffic light at the intersection north of Southwest Harrison. This time period showed the greatest mean and percent difference for the bicycle-lane and cycle-track concentrations. Future studies should further investigate the effect of proximity to signalized intersections and signal queuing on ultrafine particle concentrations. Placing study vehicles in differing proximities to intersections, along with enhanced traffic monitoring, may lead to a better understanding of geometric and traffic effects on ultrafine particle exposures. 
Traffic data from Feb. 8 and July 13 indicate a traffic pattern on Southwest Broadway of increasing traffic beginning at 5:30 a.m., elevated traffic flows past the morning peak period into the afternoon (10:45a.m.to 4 p.m.), and a decline in traffic flows beginning at 5 p.m. (Figure 6(a) and $7(\mathrm{a})$ ). The greatest exposure concentration differences of $38 \%$ and $35 \%$ (Table 1 ) for the two bicycle facilities occurred from 10:45 a.m. to 1:52 p.m. and 2:05-4:51 p.m., within the time period of elevated traffic flows. The highest exposure concentration differences from Figure 6(c) and Figure 7(c) occurred around 8:45 a.m. and 12 p.m., also within the elevated traffic flow pattern. Figure 7(c) shows decreased exposure concentration differences from 7-8 p.m. during a time period of declining traffic and lowest traffic flows. These results begin to indicate the greatest exposure level differences for the bike facilities occur when traffic was greatest. Future work will continue to collect full-day traffic and air quality measurements to track this relationship of higher exposure concentration differences associated with higher traffic levels.

A count of bicyclists prior to installation of the cycle track found that bicycle volumes peaked around 9 a.m. and again at 5:30 p.m. (around 60 bicycles per hour). The time spans of elevated motor vehicle traffic and bicyclist traffic overlap on Southwest Broadway. The above results suggest that cycle-track facilities have the greatest potential to mitigate ultrafine particle exposures for bicyclists on roadways and transportation environments with concurrently high auto use and cyclist activity.

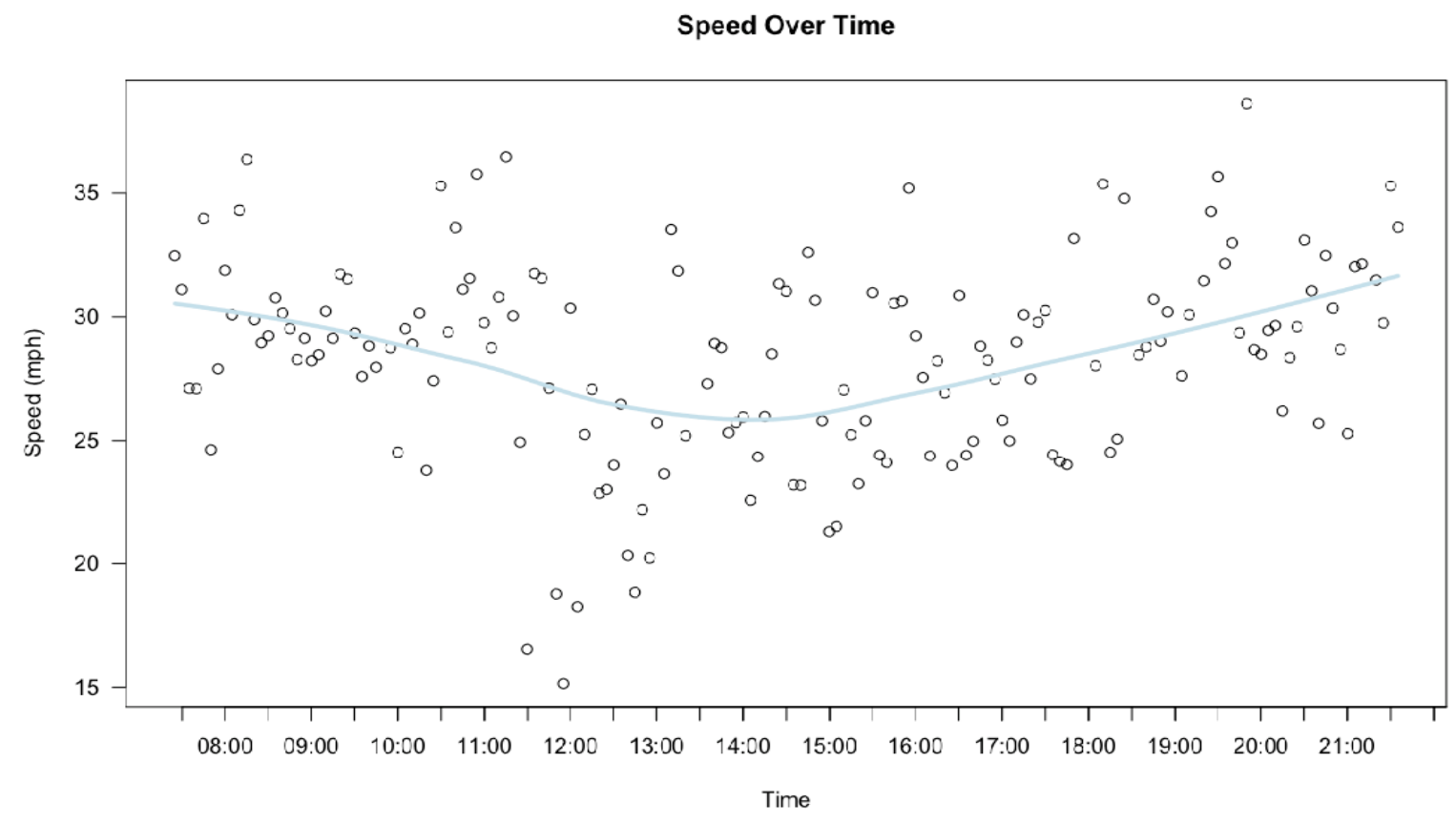

Figure 8 July 13 Speed averaged over five-minute intervals versus time with a Loess smoothing curve.

Analysis of the individual traffic variables to UFP levels using regression and functional optimization techniques did not result in a statistically significant relationship. The results of this 
analysis suggest that the interaction of traffic speed and traffic counts alone cannot functionally account for the data measured in this study. Traffic composition and wind measurements are also likely needed to understand the functional relationship between traffic and UFP levels at this study site and are to be investigated in further studies.

\subsection{PASSIVE SHIELDING WITH NOISE BARRIERS}

\subsubsection{Exposure Concentrations}

Table 1 shows mean concentration levels and range of exposure concentrations for each date at both the US-26 and I-205 monitoring sites. Using a p-value significance level of 0.05, one-sided t-tests were used to evaluate whether exposed concentrations were greater than shielded concentrations. UFP concentration levels were consistently and significantly less at shielded locations than at exposed locations on all days and at all monitoring sites. The average mean concentration for an exposed P-Trak was 23,997 particles $/ \mathrm{cm}^{3}$. UFP concentrations at exposed locations were consistently greater than shielded locations, though there was a wide range in the mean differences and percent differences (12-84\%). The range may have been related to varying wind conditions on study days.

Table 2. UFP Concentration Comparisons in particles $/ \mathrm{cm}^{3}$ (pt/cc) at One-Second Intervals for US-26 and I-205 Monitoring Locations.

\begin{tabular}{|c|c|c|c|c|c|c|c|c|c|}
\hline & $\begin{array}{c}\text { P-Trak } \\
\text { Locatio } \\
\text { n } \\
\end{array}$ & $\begin{array}{l}\text { Mean } \\
\text { Conc. } \\
\text { (pt/cc) } \\
\end{array}$ & $\begin{array}{c}\text { St. } \\
\text { Dev. } \\
\text { (pt/cc) }\end{array}$ & $\begin{array}{c}\text { Median } \\
\text { (pt/cc) }\end{array}$ & $\begin{array}{c}\text { 1-sec Conc. } \\
\text { Range } \\
\text { (pt/cc) }\end{array}$ & $\begin{array}{l}\text { Mean } \\
\text { Diff. } \\
\text { (pt/cc) }\end{array}$ & $\begin{array}{l}\text { Percen } \\
t \text { Diff. }\end{array}$ & $\begin{array}{c}\text { t- } \\
\text { value }\end{array}$ & p-value \\
\hline \multirow{10}{*}{$\stackrel{\sim}{\sim}$} & & \multicolumn{8}{|c|}{ March 24} \\
\hline & $\begin{array}{c}\text { Expose } \\
\text { d }\end{array}$ & 31,142 & 32,178 & 20,600 & $\begin{array}{l}4,290- \\
388,000\end{array}$ & \multirow[b]{2}{*}{26,236} & \multirow[b]{2}{*}{$84 \%$} & \multirow[b]{2}{*}{94.9} & \multirow{2}{*}{$<0.001$} \\
\hline & $\begin{array}{c}\text { Shielde } \\
\text { d }\end{array}$ & 4,905 & 2,345 & 4,330 & $\begin{array}{l}2,910- \\
50,700\end{array}$ & & & & \\
\hline & & \multicolumn{8}{|c|}{ April 22} \\
\hline & $\begin{array}{c}\text { Expose } \\
\text { d }\end{array}$ & 35,518 & 26,920 & 26,100 & $\begin{array}{l}4,310- \\
271,000\end{array}$ & \multirow{2}{*}{4,153} & \multirow{2}{*}{$12 \%$} & \multirow{2}{*}{21.1} & \multirow{2}{*}{$<0.001$} \\
\hline & $\begin{array}{c}\text { Shielde } \\
\text { d }\end{array}$ & 31,258 & 25,050 & 21,000 & $\begin{array}{l}4,970- \\
278,000\end{array}$ & & & & \\
\hline & & \multicolumn{8}{|c|}{ May 13} \\
\hline & $\begin{array}{c}\text { Expose } \\
\text { d }\end{array}$ & 29,270 & 27,794 & 21,000 & $\begin{array}{l}4,210- \\
450,000\end{array}$ & \multirow{2}{*}{10,183} & \multirow{2}{*}{$35 \%$} & \multirow{2}{*}{54.3} & \multirow{2}{*}{$<0.001$} \\
\hline & $\begin{array}{c}\text { Shielde } \\
\text { d }\end{array}$ & 20,126 & 15,272 & 16,200 & $\begin{array}{l}3,690- \\
316,000\end{array}$ & & & & \\
\hline & & \multicolumn{8}{|c|}{ May 27} \\
\hline \multirow{2}{*}{ ֻิ } & $\begin{array}{c}\text { Expose } \\
\text { d }\end{array}$ & 30,870 & 25,612 & 22,200 & $\begin{array}{l}5,210- \\
194,000\end{array}$ & \multirow{2}{*}{10,265} & \multirow{2}{*}{$33 \%$} & \multirow{2}{*}{57.0} & \multirow{2}{*}{$<0.001$} \\
\hline & $\begin{array}{c}\text { Shielde } \\
\text { d }\end{array}$ & 20,607 & 18,166 & 12,900 & $\begin{array}{l}5,270- \\
142,000\end{array}$ & & & & \\
\hline
\end{tabular}


The consistent and significant exposure concentration results show that those traveling on bicycle/pedestrian paths will be exposed to lower concentrations if a noise barrier separates the path from the motorized traffic. Table 2 shows a shielding effect of $12-84 \%$ of the exposed concentration levels, meaning users of shielded bicycle/pedestrian pathways are exposed to at least $12 \%$ fewer particles than those using fully exposed facilities.

A large difference between exposed and shielded sample points agrees across multiple sites and days, pointing to a broader mitigating condition rather than a unique site effect. Mean concentration values were within the expected range based on the literature review. Morawska et al. (2004) found ambient urban conditions to be on the order of a few thousand to as high as 20,000 particles $/ \mathrm{cm}^{3}$. Zhu et al. (2002) found concentrations around roadways to be up to 25 times higher than urban background conditions, expecting a peak concentration level of around 500,000 particles $/ \mathrm{cm}^{3}$. On May 12 at the US-26 site, the highest one-second peak concentration of the study was recorded on the exposed side at 450,000 particles $/ \mathrm{cm}^{3}$, but the concurrent shielded side concentration was only 45,100 particles $/ \mathrm{cm}^{3}$. Other days and locations shown in Table 1 exhibit high peak concentrations as well. No shield location observed concentrations above 400,000 particles $/ \mathrm{cm}^{3}$.

\subsubsection{Wind and Traffic Results}

Figures 9 and 10 compare wind and traffic characteristics with UFP concentration levels from both monitoring sites at 10-minute aggregations. The absolute UFP concentrations shown are the values obtained from the "exposed" P-Trak at both sites (see Figure 3 for placement locations). UFP differences are the difference between "exposed" and "shielded" P-Traks at each site.

Figure 9a displays the data collected on March 24 at the US-26 site. March 24 was the only day in which data were collected during PM peak-hour traffic rather than AM peak. Wind data were unavailable for comparison. Average shielded UFP concentrations are steadier than the exposed concentrations during the sampling period, with concentrations ranging from 3,745 to 5,747 particles $/ \mathrm{cm}^{3}$. Consequently, the mean difference tracks closely with the average exposed UFP concentrations, which are more volatile. Traffic speeds are constant until congestion at 5:30 p.m. lowers the average speed to $50 \mathrm{mph}$, during which time exposed UFP concentrations fall from 31,000 particles $/ \mathrm{cm}^{3}$ to 17,500 particles $/ \mathrm{cm}^{3}$.

Figure 9b displays the data collected on April 22 at the US-26 site. Averaged exposed UFP number concentrations peak at 9:40 a.m. with 84,213 particles $/ \mathrm{cm}^{3}$. Wind speed at this time is below $1 \mathrm{~m} / \mathrm{s}$ and northeasterly, blowing across traffic and roughly normal to the noise barrier's surface. Traffic speeds are steady at roughly $60 \mathrm{mph}$ and flow is 3,000 veh/hr/ln. At 8 a.m., average exposed UFP levels are seen to rise slightly as traffic speeds decrease from $60 \mathrm{mph}$ to 14 $\mathrm{mph}$. The mean difference tracks less closely with exposed concentrations than for March 24, and on four occasions shielded levels were greater than exposed levels. Traffic speeds are steady during these concentration inversions, but wind conditions are more varied: twice winds are from the north/northwest and twice they are from the south/southeast.

Figure 10a displays the data collected on May 13 at the US-26 site. Traffic speeds range widely from a congestion-induced low of $6 \mathrm{mph}$ at 8:10 a.m. to a steady $60 \mathrm{mph}$ when conditions clear. 
Average exposed UFP levels exhibit no apparent relation to traffic speed and, in fact, reach the morning's lowest level of 11,658 particles $/ \mathrm{cm}^{3}$ when traffic speeds slow to $6 \mathrm{mph}$, a contrast to the increase seen on April 22. Mean difference levels generally track with average exposed concentrations. Mean difference values for 9 a.m. should be disregarded due to an equipment malfunction which recorded a shielded concentration value of 0 particles $/ \mathrm{cm}^{3}$. Average shielded levels become greater than exposed levels once, beginning at 8:10 a.m. and lasting for roughly 30 minutes. Traffic flow and speeds are at their lowest values during this interval. Wind speeds are below $1 \mathrm{~m} / \mathrm{s}$ and blowing from the northwest, across traffic and roughly perpendicular to the noise barrier's surface.

Figure 10b displays the data collected on May 27 at the I-205 site. The P-Traks were located on the west side of the highway. Due to the orientation of the freeway at this location, a northwesterly wind results in vehicle emissions being blown away from the monitoring site, and from approximately 8 a.m. until the end of the time interval shown in Figure 10b, wind blew primarily from the northwest at 1-2 m/s. Average UFP concentrations recorded during this time by the exposed P-Trak ranged from 10,000 to 50,000 particles $/ \mathrm{cm}^{3}$. Early in the morning, however, at 7:10 a.m., an "ideal" easterly wind blew at roughly one $\mathrm{m} / \mathrm{s}$ directly across the freeway towards the monitoring site. Average exposed UFP concentration levels rose to 99,127 particles $/ \mathrm{cm}^{3}$ during this time period, a level at least 50,000 particles $/ \mathrm{cm}^{3}$ higher than at any other point during the morning. The mean difference during the 7:10 a.m. spike is 37,509 particles $/ \mathrm{cm}^{3}$. For the remaining duration of the data collection, the average mean difference is 8,659 particles $/ \mathrm{cm}^{3}$. Average shielded levels were greater than exposed levels once at 7:40 a.m. Wind speeds at this time had recently shifted from the southwest to the northwest and traffic flow was decreasing from 3,950 to $2,050 \mathrm{veh} / \mathrm{hr} / \mathrm{ln}$. 


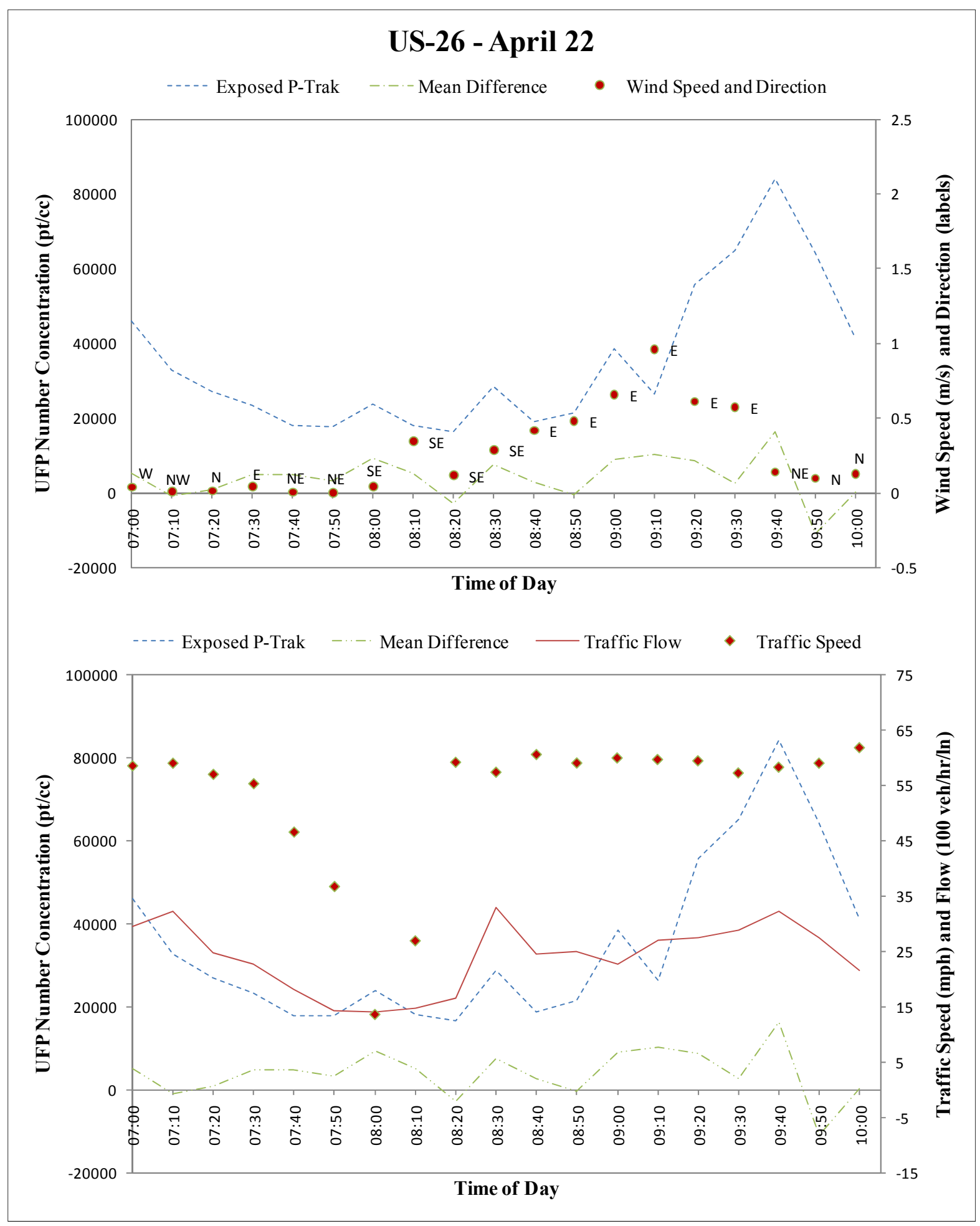

9 (a) 


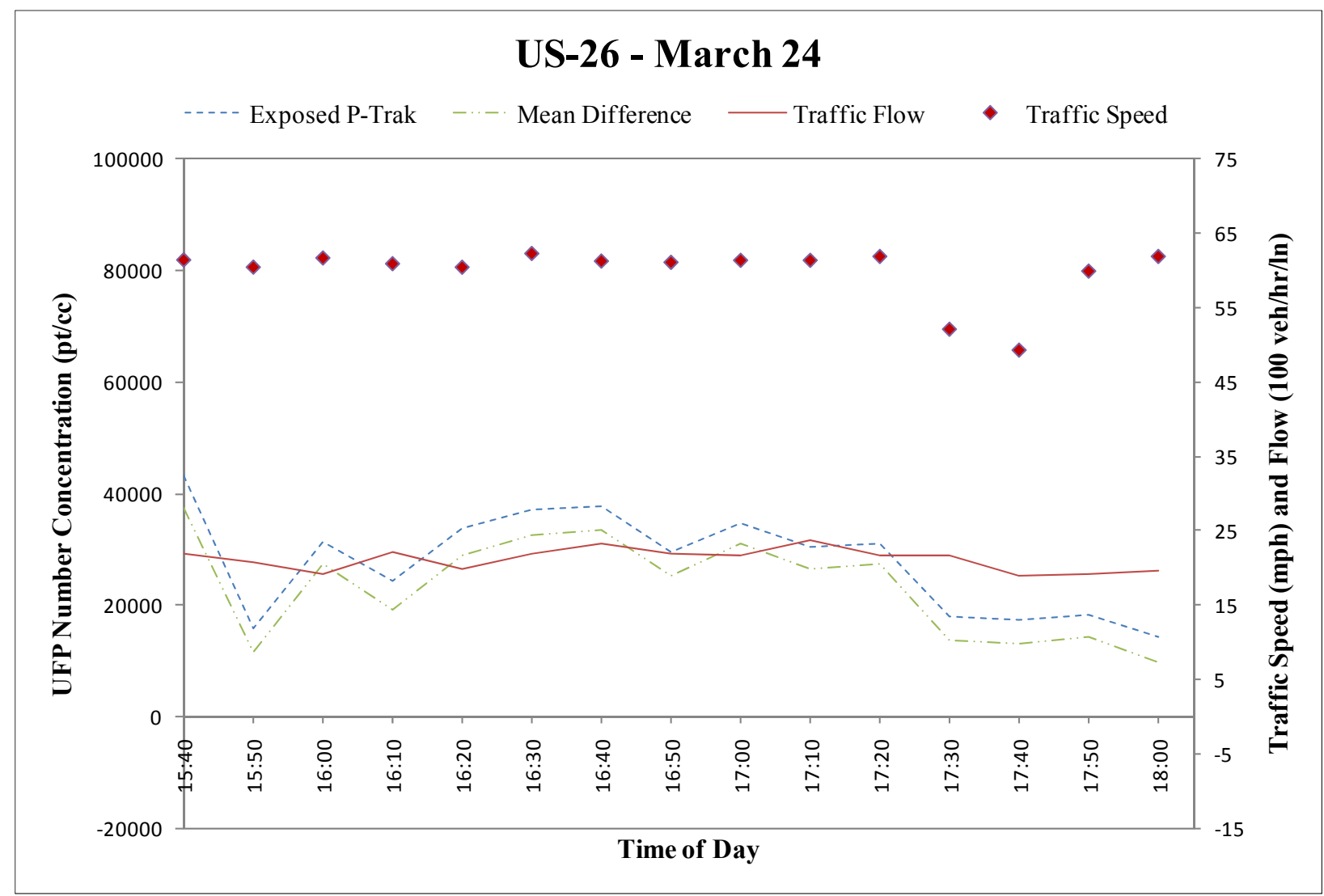

9(b)

Figure 9 Ten-minute UFP concentration aggregations in particles $/ \mathrm{cm}^{3}(\mathrm{pt} / \mathrm{cc})$ with wind and traffic characteristics on (a) March 24 and (b) April 22 [note that wind data were unavailable for March 24]. 


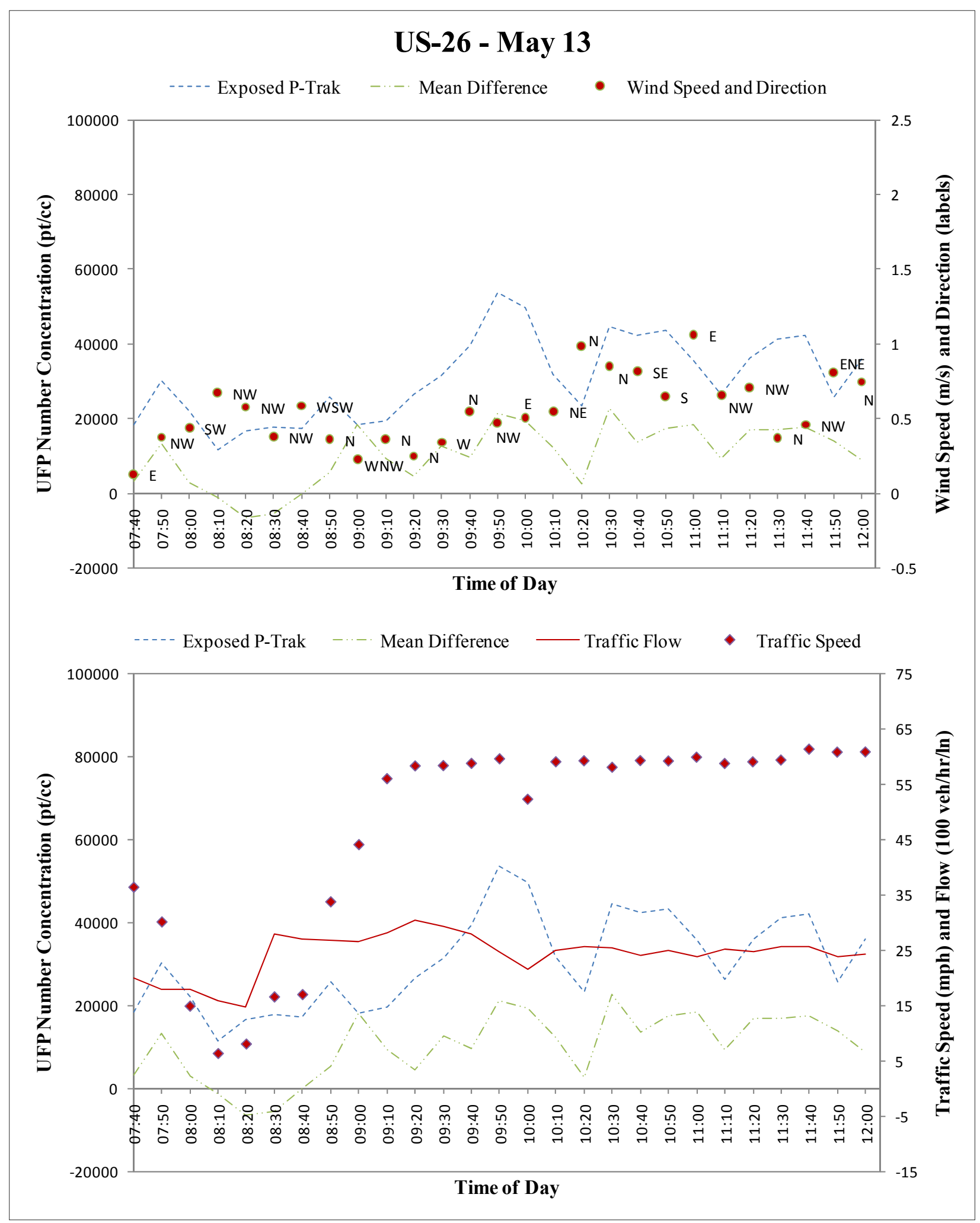

10 (a) 


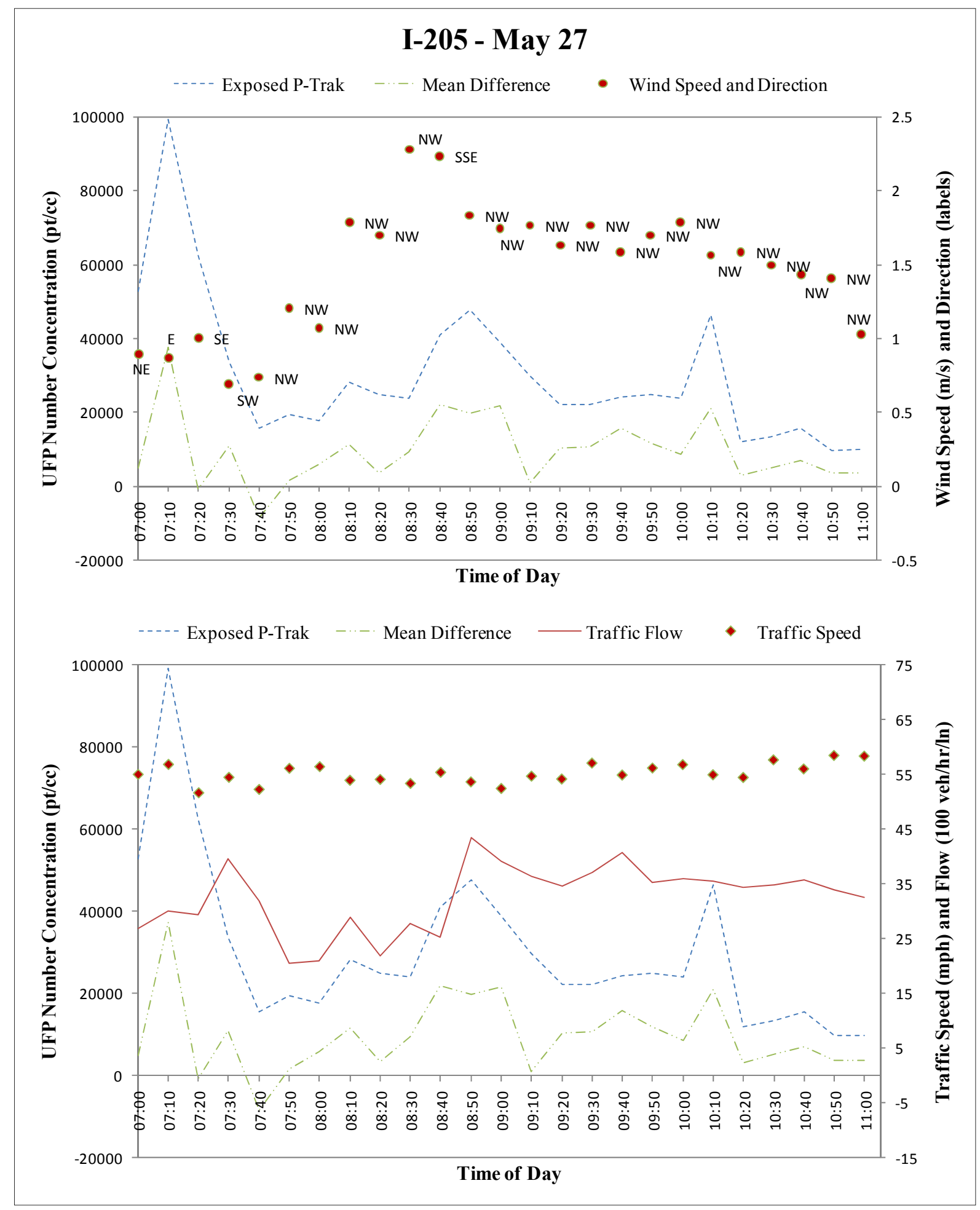

\section{0 (b)}

Figure 10 Ten-minute UFP concentration aggregations in particles $/ \mathrm{cm}^{3}(\mathrm{pt} / \mathrm{cc})$ with wind and traffic characteristics on (a) May 13 and (b) May 27. 
The I-205 site proved to be an ideal situation on May 27 for isolating wind effects on noise barrier effectiveness due to the steady traffic speeds (speed $\pm 2 \mathrm{mph}$ ). Table 3 shows the 10 minute average UFP concentrations at I-205 on May 27 during the period with easterly wind (7:10-7:20 a.m.) and an average of the ensuing northwesterly wind periods (7:40-11 a.m., excluding a south-southeasterly wind from 8:40-8:50 a.m.). The noise barrier effectively shielded pathway users $38 \%$ when winds were normal to its surface and $37 \%$ when winds were at a high angle, despite the fact that the wind directions were associated with starkly different absolute concentrations. It appears that noise barriers may shield a consistent percentage of roadway UFP regardless of roadway concentration level. The wind-direction effect on concentrations observed on I-205 emphasizes the importance of noise barriers to shield bicyclists and pedestrians if an environment has a known predominant wind. Having both wind direction scenarios on I-205 shows noise barriers may shield bicyclists and pedestrians equally well when wind blows perpendicular or at an angle to the barrier surface.

Table 3 Concentration Differences During Varying Wind Directions at I-205

\begin{tabular}{|c|c|c|c|c|c|}
\hline Time Interval & $\begin{array}{c}\text { Wind } \\
\text { Direction }\end{array}$ & $\begin{array}{c}\text { Exposed } \\
\text { P-Trak }\end{array}$ & $\begin{array}{c}\text { Shielded } \\
\text { P-Trak }\end{array}$ & $\begin{array}{c}\text { Mean } \\
\text { Diff }\end{array}$ & \% Diff \\
\hline 7:10-7:20 AM & Perpendicular & 99,127 & 61,621 & 37,506 & $38 \%$ \\
\hline 7:40-11:00* AM & Angled & 25,021 & 15,650 & 9,371 & $37 \%$ \\
\hline & $*-$ relative to noise barrier \\
& $*$ - excludes 8:40-8:50 AM
\end{tabular}

Traffic speed and flow were found to exhibit little influence over short-term changes in UFP concentration levels despite motor vehicles being the clear source of UFP. Low vehicle speeds sometimes track with low UFP levels, as seen early on May 13 (Figure 10a), and at other times track with spikes in UFP levels, as seen at 8 a.m. on April 22 (Figure 9b). There seems to be a hint of a delay effect in congestion lifting, speeds rising, and then a spike in UFP concentration is observed. However, these correlations were not consistently observed and, therefore, conclusions between traffic characteristics and the mitigating effects of noise barriers cannot be made at this time. Additional study days are needed and traffic composition data through video surveillance is needed for future work.

\subsubsection{US-26 Channel Results and QUIC Modeling}

The sound walls at the US-26 site have a unique configuration in which the barriers overlap laterally, with the bike/pedestrian path moving in between them (see Figure 11). An additional study design with the particle instruments was implemented to determine if this configuration changed concentration levels compared to the no-barrier and one-barrier wall environments. The three P-Traks were placed within the stretch of the multiuse pathway that runs through the overlapped noise barriers, Figure 11. This study setup was repeated on April 22, 2010, and May $6,2010$. 


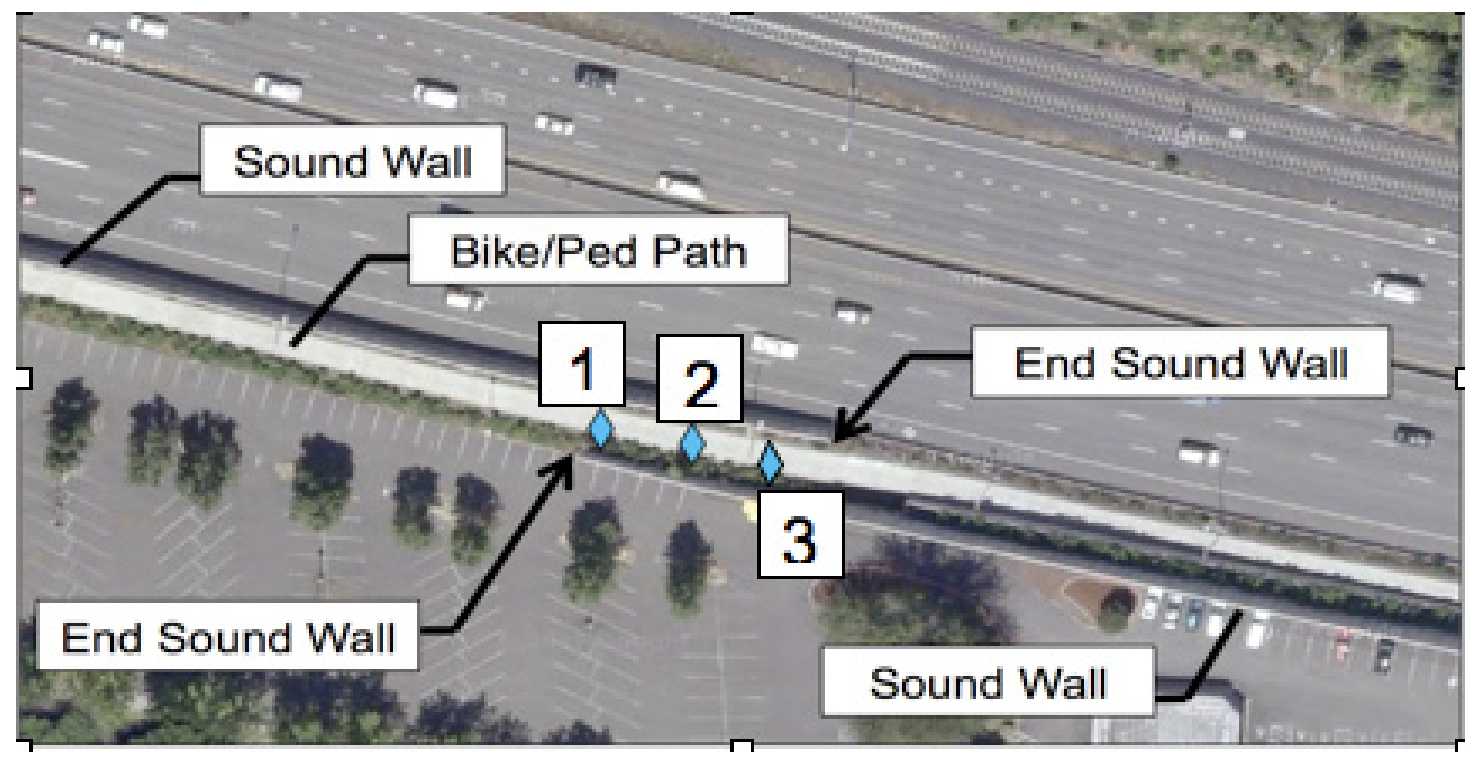

Figure 11 Study design on US-26 with all three P-Traks set up within overlapping sound walls. Blue diamonds and numbers 1-3 represent individual P-Trak instruments.

Wind speed and direction measurements were also made and found to be similar on both days, with an average speed of approximately $1.3 \mathrm{~m} / \mathrm{s}$ at $328^{\circ}$ or northwesterly direction. The configuration of the US-26 sound walls, multiuse path, vegetation, and a nearby building were built into the QUIC model domain. The initial wind conditions measured were used as inputs into the model and then the computational fluid dynamic tool of the model was run to produce wind flow fields for the study site. Results of the model are shown in Figure 12 with a vector scale of teal being equal to zero, dark blue -0.6 and dark red 0.8 . The numbers are magnitude of the wind speed in $\mathrm{m} / \mathrm{s}$ and the negative sign indicates a change in wind direction. The initial wind is coming from the northwestern direction and blowing diagonally across the road towards the sound walls.

As seen in Figure 12, wind speed increases as it wraps around the edge of the sound wall and continues to stay at a slightly elevated level, as indicated by the dark red and dark blue, until the middle of the "tunnel" or overlapping stretch of the walls. There the wind speed drops to $0 \mathrm{~m} / \mathrm{s}$ as indicated by the teal color. These wind-field results were consistent with concentration measurement results from the study design setup shown in Figure 11, with concentrations at site number 3 being the highest. This demonstrates the wind wraparound effect with wind carrying pollutants from the road into the overlap. These pollutant concentration data and wind-modeling results indicate that not only does placement of the multiuse pathway with respect to the sound walls affect exposure concentrations, but sound wall design configurations affect exposure concentrations as well. For example, edge effects, channeling effects, and how the noise barriers interact with the geometry of the landscape all can influence the exposure of pedestrians and bicyclists to air pollution generated on the roadway. 


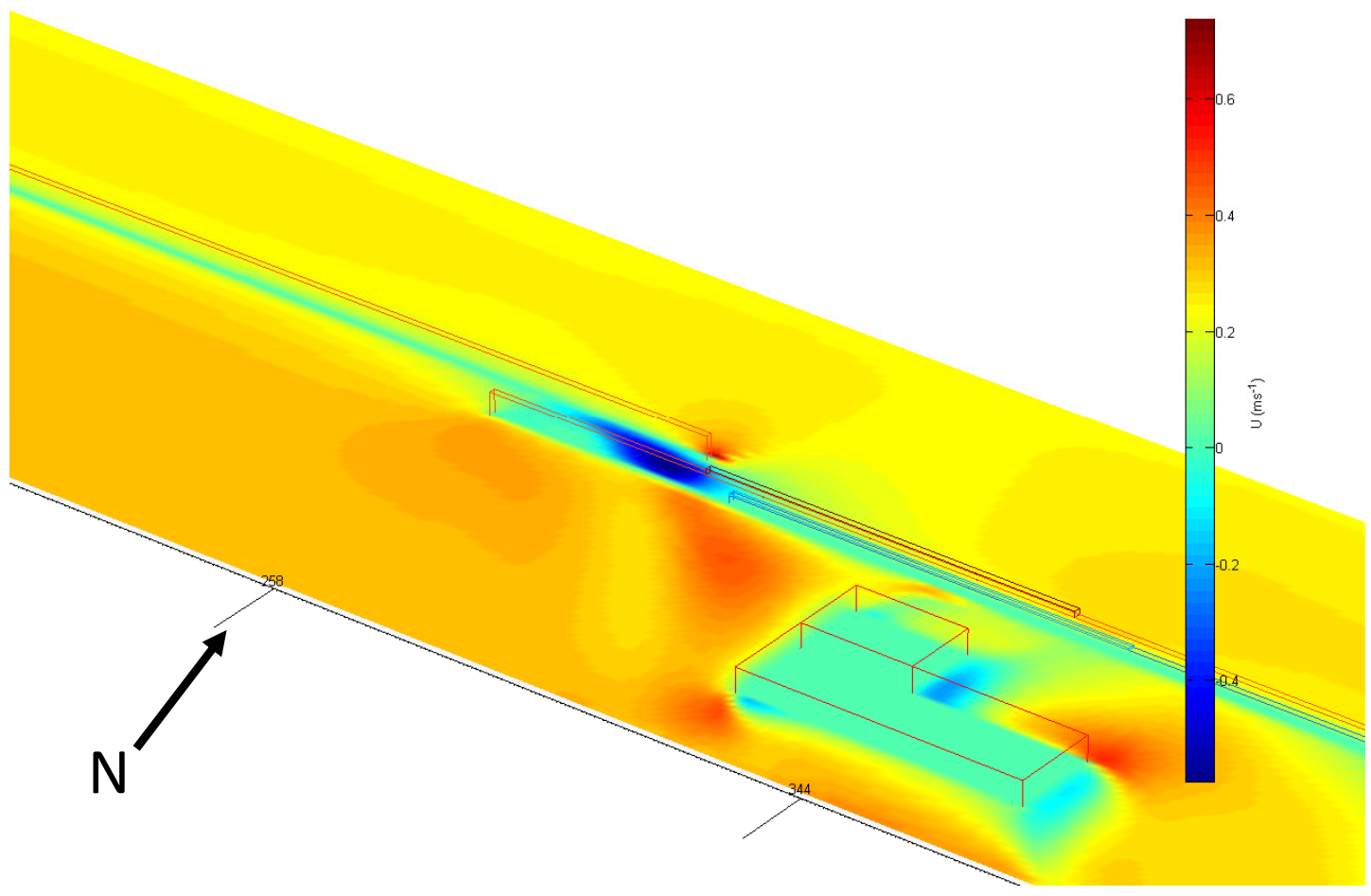

Figure 12 Wind field results from QUIC model for US-26 study site. Vector scale for wind speed field shown in color with teal being 0 , dark blue $\sim-0.6$, and dark red $\sim 0.8$. Black arrow shows north direction. 


\subsection{CONCLUSIONS}

Two different transportation microenvironments were characterized in terms of ultrafine exposure concentrations experienced by cyclists, and in terms of two possible mitigation strategies to better protect urban dwellers from transportation-related pollution. Specifically, a cycle-track design shows significantly lower UFP concentration levels, offering better protection than a typical bicycle lane in terms of air quality. Increasing the distance between traffic streams and human activity could be accomplished in other ways as well. A median or row of trees would also increase distance between cyclists and pedestrians from moving vehicles. Further studies should focus on what minimal increase in distance from traffic produces a significant decrease in pollution levels as a function of traffic parameters and meteorological characteristics. Such data would help support a variety of mitigation options depending on available space in urban transportation microenvironments.

Like the cycle track study, the barrier sound wall study showed UFP exposure concentrations significantly lower on a multiuse facility behind a sound wall. The barrier does decrease exposures directly behind. While this may seem obvious, this data now provides support for increased consideration of barrier placement when planning and constructing roadways with multiuse pathways and surrounding land uses. Considerations need to include barrier design and barrier configuration, as shown by the wind modeling results. Additionally, the study supports the use of a barrier as a mitigation tool in an elevated pollution environment in which multiple users, and especially active users, are moving through. Vegetation, a combination of wall and vegetation or elevated land masses could be used in a variety of options with sound walls to decrease exposure to ultrafine particles.

\subsection{Cycle Track}

An original method was developed to measure and compare simultaneous UFP exposure for cyclists in a traditional bicycle lane and a cycle track. UFP number concentrations were significantly higher in the typical bicycle lane than the cycle track for all study days, and nearly all study periods within those days. The higher frequency of exposure concentrations greater than $300,000-500,000 \mathrm{pt} / \mathrm{cc}$ in the bicycle lane compared to the cycle track suggests a cyclist may encounter less peak exposure concentrations in the cycle track. Additionally, the cycle track measurements in this study are the upper limit due to cross-sectional location. Significantly lower UFP number concentrations measured on the cycle track are attributable to the increased distance from the motorized traffic provided by the cycle-track configuration. Increasing the bicycle facility distance from traffic sources is difficult in cities with set road widths. A cycle track with a parking lane buffer offers a realistic solution for roads in urban areas, as parking lanes potentially lower UFP exposures for cyclists.

Traffic measurements showed the exposure concentration differences to be greatest at times of highest traffic volumes, emphasizing the importance of mitigation techniques in areas with simultaneously high volumes of motor vehicle and bicycle commuters. Initial findings show the possible effects of proximity to signalized intersections on increased UFP exposure concentration differences for a bicycle lane and a cycle track. These elements need to be studied in further detail, along with local wind and more temporal and seasonal measurements of traffic and associated UFP exposure levels. 
The findings of this study show a cycle-track design may be more protective for cyclists than a traditional bicycle lane in terms of lowering exposure concentrations of ultrafine particles. This, of course, must be balanced against other factors, such as vehicle-bicycle conflicts at intersections and other design considerations. Based on these initial findings, understanding roadway and traffic effects on exposure levels can help guide bicycle facility design and pinpoint locations in which mitigation of exposure levels by placement of facilities such as cycle tracks may be most important.

\subsection{Noise Barrier}

Understanding the influence of traffic and the physical environment on UFP concentrations is an essential component of evaluating human exposure to pollution in urban environments. In this study, we examine the UFP exposure of bicyclists and pedestrians on multiuse paths adjacent to freeway noise barriers. Using concurrent traffic, wind and air quality measurements, UFP levels were found to be significantly higher along multiuse paths placed in front of noise barriers (on the freeway side) than those behind the noise barriers (on the residential side). The shielding effectiveness of the noise barrier varied by study site and day, but the effectiveness did not appear to relate to traffic or wind conditions. The barrier was also consistently effective at reducing pathway concentrations for highly varying exposed-side concentrations. Utilizing preexisting freeway right-of-way near noise barriers for bicycle/pedestrian pathways is a costeffective way to provide non-motorized transportation facilities and promote the use of active transportation modes, especially in urban environments where space is at a premium. But these facilities can expose bicyclists and pedestrians to UFP levels much higher than urban background levels. This research shows that increased UFP exposure can be partially mitigated by placing the multiuse path on the side of the noise barrier away from freeway traffic - though shielded exposure rates are still above typical urban background levels. Further research into airflow and pollutant dispersion around noise barriers is needed to show the path and barrier design conditions which are most effective at UFP exposure mitigation. For example, the effectiveness of varying barrier heights and materials is not yet known, nor is the effect of spacing between roadway and wall, and between wall and path. Future research will also investigate more varied traffic congestion conditions to help determine which traffic management strategies can further mitigate road-user exposure to UFP. 


\section{REFERENCES}

Berghmans, P., Bleux, N., Int Panis, L., Mishra, V.K., Torfs, R., and M. Van Poppel. Exposure assessment of a cyclist to $\mathrm{PM}_{10}$ and ultrafine particles. Science of the Total Environment, 407, 2009, pp. 1286-1298.

Boogaard, H., Borgman, F., Kamminga, J., and G. Hoek. Exposure to ultrafine and fine particles and noise during cycling and driving in 11 Dutch cities. Atmospheric Environment, 43, 2009, pp. 4234-4242.

Bowker, G.E., Baldauf, R., Isakov, V., Khlystov, A., and Petersen, W. The effects of roadside structures on the transport and dispersion of ultrafine particles from highways. Atmospheric environment, 41, 2007, pp. 8128-8139.

Hagler, G.S.W., Baldauf, R.W., Thoma, E.D., Long, T.R., Snow, R.F., Kinsey, J.S., Oudejans, L., and Gullett, B.K. Ultrafine particles near a major roadway in Raleigh, North Carolina: Downwind attenuation and correlation with traffic-related pollutants. Atmospheric Environment, 43, 2009, pp. 1229-1234.

Harrison, R.M., Jones, M., and G. Collins. Measurements of the physical properties of particles in the urban atmosphere. Atmospheric Environment, 33, 1999, pp. 309-321.

Harrison, R.M., Shi, J.P., Xi, S. Khan, A., Mark, D., Kinnersley, R. and J. Yin. Measurement of number, mass, and size distribution of particles in the atmosphere. Philosophical Transactions: Mathematical, Physical, and Engineering Sciences, 358, 2000, pp. 2567-2580.

Holscher, N., Hoffer, R., Niemann, H-J., Brilon, W., Romberg, E. Wind tunnel experiments on micro-scale dispersion of exhausts from motorways. Science of the Total Environment 134, 1993, pp. 71-79.

Jensen, S.U., Rosenkilde, C. and N. Jensen. Road safety and perceived risk of cycle facilities in Copenhagen. Produced for the Municipality of Copenhagen. Produced by Trafitec. http://www.ecf.com/files/2/12/16/070503_Cycle_Tracks_Copenhagen.pdf

Junker, M., Kasper, M., Roosli, M., Camenzind, M., Kunzli, N., and C. Monn. Airborne particle number profiles, particle mass distributions and particle-bound $\mathrm{PAH}$ concentrations within the city environment of Basel: an assessment part of the BRISKA Project. Atmospheric Environment, 34, 2000, pp. 3171-3181. 
Kaur, S., Nieuwenhuijsen, and R.N. Colvile. Fine particulate matter and carbon monoxide exposure concentrations in urban street transport microenvironments. Atmospheric Environment, 41, 2007, pp. 4781-4810.

Kaur, S. and M.J. Nieuwenhuijsen. Determinants of Personal Exposure to $\mathrm{PM}_{2.5}$, Ultrafine Particle Counts, and CO in a Transport Microenvironment. Environmental Science and Technology, 43, 2009, pp. 4737-4743

Kittelson, D.B. Engines and nanoparticles: a review. Journal of Aerosol Science, 29, 1998, pp. 575-588.

Klingner, R. E., McNerney, M. T., and Busch-Vishniac, I. Design Guide for Highway Noise Barriers. Report No. FHWA/TX-04/0-1471-4, Austin, TX, Federal Highway Administration, 2003.

Li, N., Sioutas, C., Cho, A., Schmitz, D., Misra, C. Sempf, J., Wang, M. Oberley, T., Froines, J., and A. Nel. Ultrafine particulate pollutants induce oxidative stress and mitochondrial damage. Environmental Health Perspectives, 111, 2003, pp. 455-460

Lidman, J.K. Effect of a noise wall on snow accumulation and air quality. Transportation Research 42 Record 1033, 1985, pp. 79-88.

McNabola, A., Broderick, B.M., and L.W. Gill. Optimal cycling and walking speed for minimum absorption of traffic emissions in the lungs. Journal of Environmental Science and Health, Part A, Toxic/hazardous substances \& environmental engineering, 42, 2007, pp. 1999-2007.

McNabola, A., Broderick, B.M., and L.W. Gill. Relative exposure to fine particulate matter and VOCs between transport microenvironments in Dublin: Personal exposure and uptake. Atmospheric Environment, 42, 2008, pp. 6496-6512.

Møller, P., Folkmann, J. K., Forchhammer, L., Bräuner, E.V. Danielsen, P.H., Risom, L. and S. Loft. Air pollution, oxidative damage to DNA, and carcinogenesis. Cancer Letters, 266, 2008, pp. 84-97.

Morawska, L., Moore, M.R., and Ristovski, Z.D. Health impacts of ultrafine particles: Desktop literature review and analysis. Report to the Australian Department of the Environment and Heritage, 2004.

O’Donoghue, R.T., Gill, L.W., McKevitt, R.T., and B.M. Broderick. Exposure to hydrocarbon concentrations while commuting or exercising in Dublin. Environmental International, 33, 2007, pp. 1-8. 
Ristovsk, Z.D., Morawska, L., Bofinger, N.D., and J. Hitchins. Submicrometer and Supermicrometer Particles from Diesel Vehicle Emissions. Environmental Science and Technology, 32, 1998, pp. 2033-2042.

Seaton, A., Godden, D., MacNee, W. and K. Donaldson. Particulate air pollution and acute health effects. The Lancet, 345, 1995, pp. 176-178.

Thai, A., McKendry, I. and M. Brauer. Particulate matter exposure along designated bicycle routes in Vancouver, British Columbia. Science of the Total Environment, 405, 2008, pp. 26-35.

Van Wijnen, J.H., Verhoeff, A.P., Jans, H.W.A., and M. van Bruggen. The exposure of cyclists, car drivers, and pedestrians to traffic-related air pollutants. International Archives of Occupational and Environmental Health, 67, 1995, pp. 187-193.

Veerabhadra Swamy, K.T., Lokesh, K.S. Lead dispersion studies along highways. Indian Journal of Environmental Health, 35 (33), 1993, pp. 205-209.

Vinzents, P.S. Moller, P., Sorensen, M., Knudsen, L.E., Hertel, O., Jensen, F.P., Schibye, B., and S. Loft. Personal Exposure to Ultrafine Particles and Oxidative DNA Damage. Environmental Health Persepctives, 113, 2005, pp. 1485-1490.

Zhang, J. and L. Morawska. Combustion sources of particles: 2. Emission factors and measurement methods. Chemosphere, 49, 2002, pp. 1059-1074.

Zhu, Y.F., Hinds, W.C., Kim, S., Shen, S., Sioutas, C. Study of ultrafine particles near a major highway with heavy-duty diesel traffic. Atmospheric Environment 36, 2002, pp. $4323-$ 4335 . 



\section{SOTREC \\ AND EDUCATION CONSORTIUM}

P.O. Box 751

Portland, OR 97207

OTREC is dedicated to stimulating and conducting collaborative multi-disciplinary research on multi-modal surface transportation issues, educating a diverse array of current practitioners and future leaders in the transportation field, and encouraging implementation of relevant research results. 